\title{
Limited potential for bird migration to disperse plants to cooler latitudes
}

https://doi.org/10.1038/s41586-021-03665-2

Received: 15 July 2020

Accepted: 21 May 2021

Published online: 23 June 2021

Check for updates

\author{
Juan P. González-Varo ${ }^{\bowtie}$, Beatriz Rumeu', Jörg Albrecht ${ }^{2}$, Juan M. Arroyo ${ }^{3}$, Rafael S. Bueno ${ }^{4}$, \\ Tamara Burgos ${ }^{5}$, Luís P. da Silva ${ }^{6}$, Gema Escribano-Ávila ${ }^{7}$, Nina Farwig ${ }^{8}$, Daniel García ${ }^{9}$, \\ Ruben H. Heleno ${ }^{10}$, Juan C. Illera ${ }^{9}$, Pedro Jordano ${ }^{3}$, Przemystaw Kurek ${ }^{11}$, Benno I. Simmons ${ }^{12}$, \\ Emilio Virgós ${ }^{5}$, William J. Sutherland ${ }^{13}$ \& Anna Traveset ${ }^{7}$
}

Climate change is forcing the redistribution of life on Earth at an unprecedented velocity $^{1,2}$. Migratory birds are thought to help plants to track climate change through long-distance seed dispersal ${ }^{3,4}$. However, seeds may be consistently dispersed towards cooler or warmer latitudes depending on whether the fruiting period of a plant species coincides with northward or southward migrations. Here we assess the potential of plant communities to keep pace with climate change through long-distance seed dispersal by migratory birds. To do so, we combine phenological and migration information with data on 949 seed-dispersal interactions between 46 bird and 81 plant species from 13 woodland communities across Europe. Most of the plant species (86\%) in these communities are dispersed by birds migrating south, whereas only $35 \%$ are dispersed by birds migrating north; the latter subset is phylogenetically clustered in lineages that have fruiting periods that overlap with the spring migration. Moreover, the majority of this critical dispersal service northwards is provided by only a few Palaearctic migrant species. The potential of migratory birds to assist a small, non-random sample of plants to track climate change latitudinally is expected to strongly influence the formation of novel plant communities, and thus affect their ecosystem functions and community assembly at higher trophic levels.
Anthropogenic climate change is forcing the redistribution of life on Earth at an unprecedented rate ${ }^{1,2}$. The distribution of organisms is constrained by the climatic conditions that they can tolerate (known as their climatic envelope $)^{5}$. Driven by global warming, climatic envelopes are shifting towards higher (cooler) latitudes ${ }^{6,7}$. The mean global velocity at which organisms need to shift their distributional range to retain the same temperatures has been estimated at $4.2 \mathrm{~km}$ per decade, although estimates exceed $100 \mathrm{~km}$ per decade in some region $\mathrm{s}^{2,8}$. A crucial question is whether species and locally adapted genotypes will be able to move sufficiently fast to track a rapidly changing climate, which depends on their dispersal capacities ${ }^{5,7,10}$. Tackling this issue is key for understanding and predicting the effects of climate change on biological communities and the ecosystem functions that they mediate, including those that affect human welfare and even climate itself (via vegetation shifts) ${ }^{1,11}$.

Plants are the cornerstone of terrestrial ecosystems, but there is a major knowledge gap regarding their dispersal abilities and latitudinal range shifts under current rates of global warming ${ }^{5-7,9-11}$. Dispersal beyond range edges is necessary for plant species to colonize novel areas that become suitable owing to climate change ${ }^{6,12}$, whereas dispersal within species ranges allows the immigration of genotypes from warm-adapted populations to cooler areas that are becoming warmer ${ }^{13}$. However, plants are sessile and the dispersal of their seeds (the process that allows new individuals to recruit far away) generally occurs within $1 \mathrm{~km}$ of source plants ${ }^{14-17}$. Although local dispersal is crucial for plant recruitment, it is clearly insufficient to track current climate change, particularly in plants with generation times of several years to decades ${ }^{12,18}$. Therefore, long-distance seed dispersal is required; however, we need a better mechanistic understanding of these less frequent-yet highly relevantseed-dispersal events ${ }^{19}$. Migratory birds have recently been identified as possible suppliers of these dispersal events ${ }^{3,4}$, because these migrants can transport viable seeds over tens or even hundreds of kilometres in short time periods ${ }^{3,20,21}$. The most notable evidence comes from the Canary Islands in the Atlantic Ocean, where about $1.2 \%$ of birds caught in migration by Eleonora's falcons (Falco eleonorae) were found to carry seeds in their guts from the mainland, over $170 \mathrm{~km}$ away ${ }^{20}$. Further evidence comes from island colonization by fleshy-fruited plants ${ }^{22,23}$, mechanistic models parameterized with empirical data of migratory movements and gut retention times of ingested seeds ${ }^{24}$, and large-scale patterns of

'Departamento de Biología, IVAGRO, Universidad de Cádiz, Puerto Real, Spain. ${ }^{2}$ Senckenberg Biodiversity and Climate Research Centre (BiK-F), Frankfurt am Main, Germany. ${ }^{3}$ Integrative

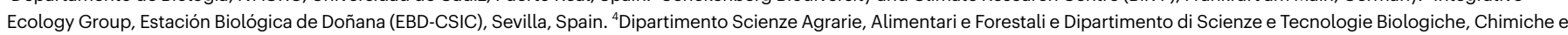
Farmaceutiche, Università degli Studi di Palermo, Palermo, Italy. ${ }^{5}$ Departamento de Biología y Geología, Física y Química Inorgánica, Universidad Rey Juan Carlos, Móstoles, Spain. ${ }^{6} \mathrm{CIBIO}-\mathrm{InBIO}$, Research Center in Biodiversity and Genetic Resources, University of Porto, Vairão, Portugal. ${ }^{7}$ Global Change Research Group, Mediterranean Institute of Advanced Studies (CSIC-UIB), Esporles, Spain. ${ }^{8}$ Conservation Ecology, Department of Biology, University of Marburg, Marburg, Germany. ${ }^{9}$ Research Unit of Biodiversity (UO-CSIC-PA), Oviedo University, Mieres, Spain. ${ }^{10} \mathrm{CFE}$ - Centre for Functional Ecology, Department of Life Sciences, University of Coimbra, Coimbra, Portugal. ${ }^{11}$ Department of Plant Ecology and Environmental Protection, Adam Mickiewicz University, Poznań, Poland. ${ }^{12}$ Centre for Ecology and Conservation, College of Life and Environmental Sciences, University of Exeter, Penryn, UK. ${ }^{13}$ Conservation Science Group, Department of Zoology, University of Cambridge, Cambridge, UK. ${ }^{\circledR}$ e-mail: juanpe.varo@uca.es 


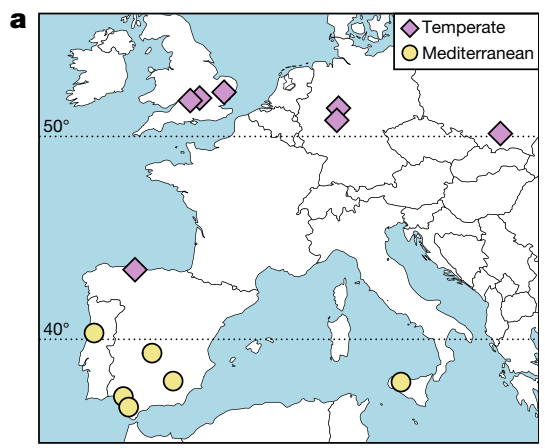

Fig. 1 | Location of the 13 European seed-dispersal networks we studied, and network with bird-plant interactions in relation to bird migration. a, Study sites in Portugal, Spain, UK, Germany, Italy and Poland. Symbols denote the biome of the locations (Mediterranean or temperate). b, Hypothetical seed-dispersal network illustrating how the weight of each pairwise interaction $i j$ can be partitioned in relation to the migratory state of the bird using the

plant genetic structure along migratory routes ${ }^{25}$ (Supplementary Discussion 1 ). Although such dispersal events seem rare, they are numerically compensated for by the fact that billions of birds migrate every year worldwide through seasonal and directional displacements that are highly predictable in space and time ${ }^{26}$.

In the Northern Hemisphere, birds typically migrate towards the Equator in autumn (postnuptial migration) and towards the North Pole in spring (prenuptial migration) ${ }^{26}$. Thus, plants could be consistently dispersed towards warmer or cooler latitudes depending on whether their fruiting period overlaps with southward or northward bird migrations, respectively (Extended Data Fig. 1). The relationship between migration directionality, plant phenology and dispersal potential towards cooler latitudes has, to our knowledge, been overlooked to date, despite this being crucial to predict the ability of plants to track climate change $\mathrm{e}^{5,6,11}$. In this Article, we provide an assessment of the potential of European plant communities to keep pace with climate change through long-distance seed dispersal towards cooler latitudes. We combined data on fruiting phenology and bird migration with information on pairwise interactions between frugivorous birds and fleshy-fruited plants from 13 woodland communities distributed across Europe (Fig. 1a). We focused on fleshy-fruited plants because many of their seed dispersers are migratory birds that far outnumber (both numerically and functionally) resident frugivores in European forests and woodlands $\mathrm{s}^{27,28}$. Moreover, fleshy-fruited plants are an important component of woody floras that account for a mean of $35 \%$ of species in temperate forests and $44 \%$ in Mediterranean woodlands ${ }^{29}$.

We used data on seed-dispersal networks (that is, local communities of interacting bird and plant species) with links that describe the presence and intensity of pairwise interactions ${ }^{30}$; in this case, the quantity of seeds of each plant species that is dispersed by each bird species (Fig. 1b). Importantly for the purpose of this study, all networks were sampled all year-round, covering the entire fruiting phenology of all plant species and the entire migration periods of all migratory birds (Extended Data Table 1 ). The 13 study networks were distributed across the Mediterranean $(n=6)$ and temperate $(n=7)$ biomes of Europe (Fig. 1a), and included a total of 949 interactions (range $=24-204$ per network) between 46 bird species (range $=8-21$ ) and 81 plant species (range $=8-29)$ (Extended Data Tables 1,2). Most plant species were woody (89\%), and the remainder were herbs (Extended Data Table 2).

In each network, we partitioned each bird-plant interaction according to the migratory state of the bird: migrating southwards, migrating northwards and non-migrating (Fig. 1b). To do so, we collated and combined information on the fruiting phenology of the plants and the phenology of bird migrations (Extended Data Fig. 1) (Methods). Then, for each plant species $i$, we calculated the fraction of its total interaction weight $\left(F_{i}\right)$ that corresponds to interactions with each of the migratory states of the birds

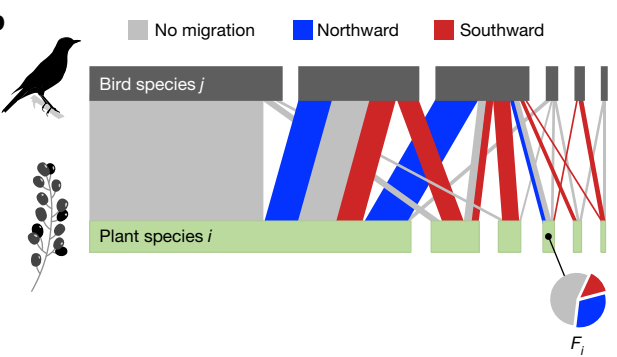

phenological overlaps between the seed-dispersal period of plant species and periods of no migration, northward migration and southward migration of bird species (Extended Data Fig. 1). $F_{i}$ are the interaction frequency values out of the total interaction weight of each plant species $i$ that was with birds migrating southwards or northwards or with non-migrating birds.

(Fig.1b,Extended Data Fig. 2). These calculations considered whether bird populations were full migrants or partial migrants, in which a fraction of the population migrates and the rest stays as residents ${ }^{26}$ (Methods).

Our analysis tested whether the proportion of plant species interacting with migrating birds (prevalence), the frequency of such interactions and the number of bird species dispersing each plant species were significantly associated with the migration direction (southward or northward) (Methods). We used generalized linear mixed models to account for the non-normal error distributions and repeated measures per network and plant species. We also tested for differences between Mediterranean and temperate biomes in potential for plants to be dispersed towards cooler latitudes, because these biomes differ in fruiting seasonality: Mediterranean woodlands are characterized by longer fruiting seasons ${ }^{29}$, which increase the probability of phenological overlap with the northward spring migration. We found that the majority (86\%) of plant species across European communities are dispersed by birds migrating southwards, whereas only about one third (35\%) are dispersed by northward-migrating birds (direction: $P<0.001$ ) (Fig. 2a, Extended Data Table 3). This trend was consistent across biomes, but was less pronounced in Mediterranean (80\% and $42 \%$ for southward and northward migrations, respectively) than in temperate communities (89\% and 29\% for southward and northward migrations, respectively) (interaction of biome $\times$ direction, $P=0.008$ ) (Fig. 2a, Extended Data Table 3). The sums of these percentages are greater than $100 \%$ because interactions with southward-and northward-migrating birds are not mutually exclusive (Fig. 1b), and many plant species are dispersed during both migrations (Extended Data Fig. 2, Supplementary Methods). The interaction frequency between plants and migrating birds was also much higher during the southward (36\%) than during the northward (11\%) migration (direction, $P<0.001$ ) (Fig. 2b, Extended Data Table 3). This trend was also consistent across biomes, but was more pronounced in Mediterranean communities (40\% and $9 \%$ for southward and northward migrations, respectively) than in temperate communities ( $32 \%$ and $13 \%$ for southward and northward migrations, respectively) (interaction of direction $\times$ biome, $P=0.011$ ) (Fig. 2b). Finally, plants were dispersed by more bird species migrating southwards than northwards (estimated mean $=2.9$ and 2.3 species per plant, respectively; direction, $P=0.017$ ), a small but consistent difference across biomes (Fig. 2c, Extended Data Table 3). Importantly, these results were not an artefact of analysing networks that were sampled with different methods (Supplementary Discussion 2). Our findings are congruent with general patterns in fruiting seasonality and bird migrations, as the fruiting peak in temperate and Mediterranean plant communities occurs between late summer and early winter ${ }^{29}$, when migratory birds move southwards ${ }^{26}$.

We further tested whether closely related plant species tend to have similar seed-dispersal interactions with birds migrating southwards or 


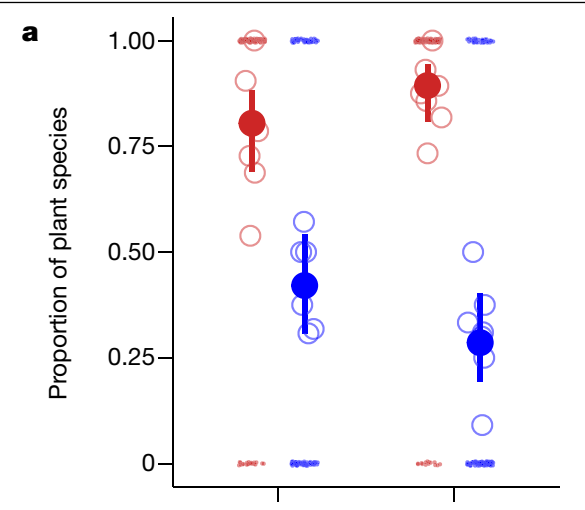

\section{d}
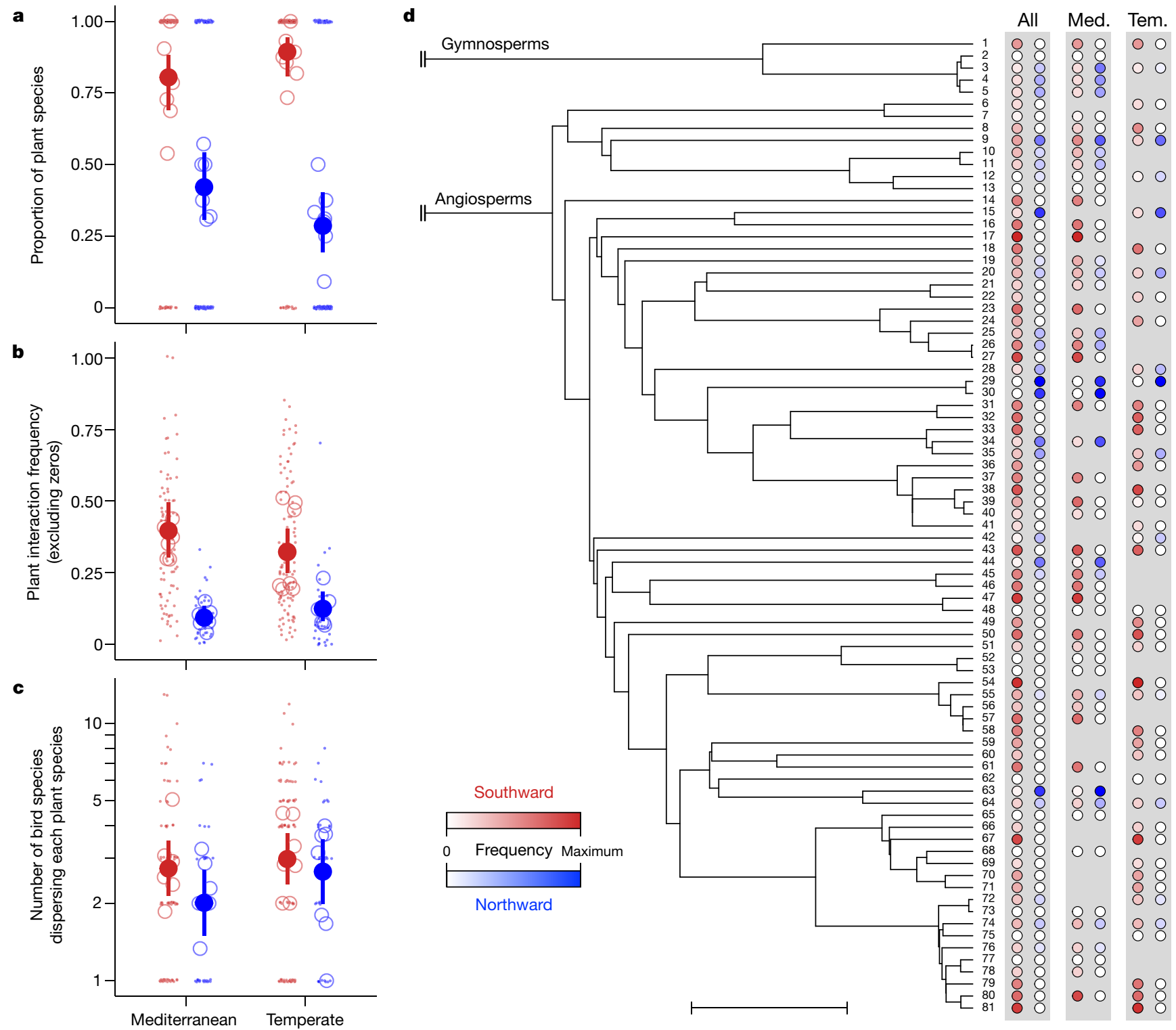

Fig. 2 | Seed-dispersal interactions of plants with migratory birds in relation to southward and northward migration and Mediterranean or temperate biome. a-c, Large dots and bars denote means $\pm 95 \%$ confidence intervals estimated by generalized linear mixed models predicting the proportion of plant species interacting with birds during migration ( $n=434$ observations from 13 networks across plant species and directions) (a), the frequency of interactions with migrating birds when these occurred (zeros excluded) ( $n=260$ observations), out of the total seed-dispersal interactions (b), and the number of bird species dispersing each plant species $(n=260$ observations) (c). Circles denote mean values for each seed-dispersal network;

tiny dots denote plant-level data.d, Dated phylogeny of the fleshy-fruited plants in the studied networks, with the root at 325 million years ago (shown in Extended Data Fig. 3). Scale bar, 50 million years. Numbers at the tips indicate species' codes (see species names in Extended Data Fig. 3). Coloured circles at the right of the tips indicate species-level means in interaction frequency $\left(F_{i}\right)$ with birds migrating southwards or northwards (red and blue colour gradients, respectively) calculated across all networks (all) and, separately, for Mediterranean (Med.) and temperate (tem.) networks (maximum frequency means in all, Mediterranean and temperate, respectively: southward $=0.80$, 0.80 and 0.76 ; northward $=0.30,0.23$ and 0.34 ). northwards. The rationale is that the fruiting period of plants shows a phylogenetic signal ${ }^{31}$ and can thus be related to the phenological overlap with seasonal migrations (Extended Data Fig. 1b). We calculated the mean interaction frequency with birds migrating in either direction at the plant-species level, both across all networks ( $n=81$ species) and separately across Mediterranean ( $n=53$ species) and temperate ( $n=45$ species) networks (Fig. $2 \mathrm{~d}$ ). We found no phylogenetic signal for interaction frequency with southward migrants (all Pagel's $\lambda \ll 0.01$, $P=1.0$ ). Conversely, we detected a strong phylogenetic signal for interaction frequency with northward migrants, both when considering all networks $\left(\lambda=0.944, P=1.2 \times 10^{-6}\right)$ and when considering plants from Mediterranean $(\lambda=0.895, P=0.025)$ or temperate $(\lambda=0.999, P=0.001)$ networks separately. We also detected significant phylogenetic signal for phenological variables describing the fruiting period of the study plants (specifically, the start and end dates, and the period length) (Extended Data Fig. 3). Accordingly, plant lineages that are frequently dispersed by northward-migrating birds are characterized by long fruiting periods (for example, Juniperus spp.; labels 3-5 in Fig. 2d) or late fruiting periods that extend until the spring of the next calendar year (for example, Hedera spp.; labels 29-30 in Fig. 2d). By contrast, plant lineages that are not dispersed by northward migrants are characterized by short fruiting periods between summer and early winter (for example, Arum spp. and Prunus spp.; labels 6-7 and 65-71 in Fig. $2 d$, respectively). Our results indicate that the potential of plants to track 
Palaearctic migrants

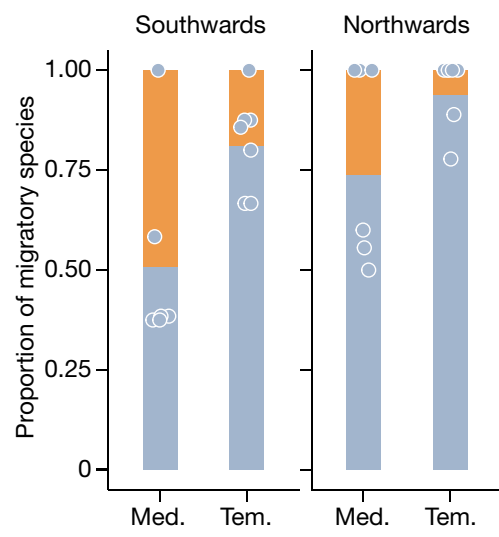

Afro-Palaearctic migrants

b

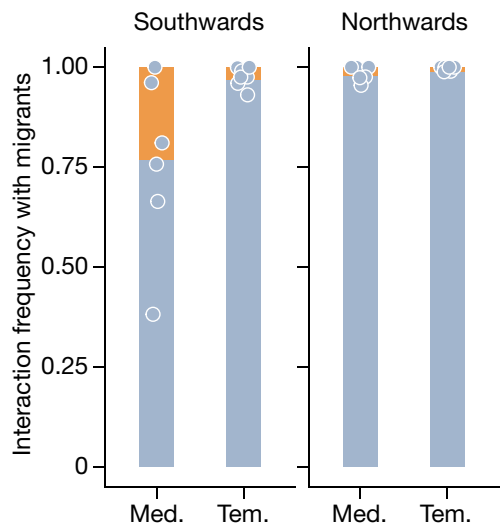

C

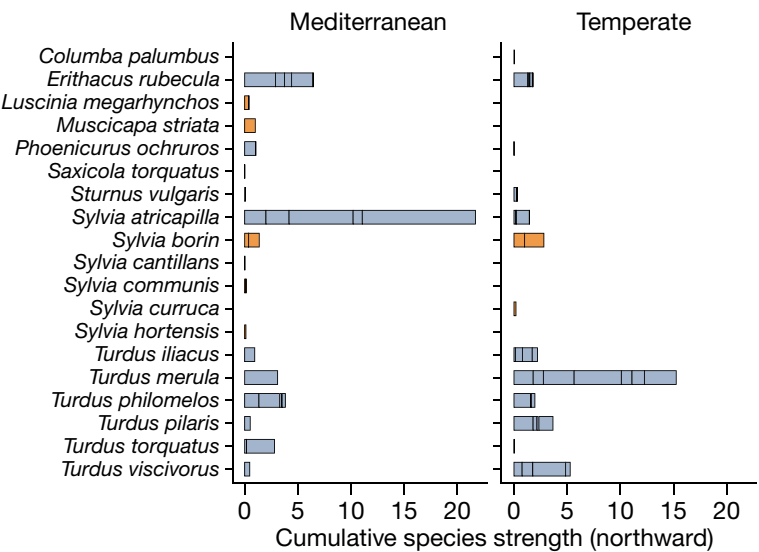

Fig. 3 | Relevance of Palaearctic and Afro-Palaearctic migratory birds dispersing seeds during their southward and northward migration in Mediterranean and temperate communities. a, Mean proportion of Palaearctic (grey) and Afro-Palaearctic (orange) species (wintering ranges in Europe and Africa north of the Sahara, and in sub-Saharan Africa, respectively) dispersing seeds while migrating, in relation to migration direction (southwards (left) or northwards (right)) and biome (Mediterranean or temperate). b, Mean relative contributions of Palaearctic and Afro-Palaearctic migrants to network-level interaction weight with migratory birds during their southward (left) and northward (right) migrations in Mediterranean and temperate communities. Circles in $\mathbf{a}, \mathbf{b}$ denote network-level observations for
Palaearctic migrants. c, Relevance of bird species for seed dispersal towards cooler latitudes across Mediterranean (left) and temperate (right) fleshy-fruited plant communities, measured as the cumulative strength of bird species in subnetworks of interactions between plants and birds migrating northwards (blue links in Fig. 1b). Species strength quantifies the relevance of a bird species across the whole plant community; high cumulative values are found in bird species with high strength values in several subnetworks within each biome. Bird drawings represent the three most relevant species in each biome (from left to right, E. rubecula, S. atricapilla, T. philomelos, T. merula, T. pilaris and T. viscivorus). Illustrations by Juan M. Varela. climate change is clustered in particular lineages, which suggests that the novel communities that may emerge in northern latitudes in the long term will incorporate non-random subsets of the evolutionary tree of southern floras. This phylogenetic filtering might have unanticipated consequences for ecosystem function ${ }^{32}$ and community composition at higher trophic levels ${ }^{33,34}$.

European migratory birds can be classified into two distinct groups according to their migratory strategy: Palaearctic migrants winter in southernEuropeand northern Africa, whereas Afro-Palaearctic migrants winter in sub-Saharan $\mathrm{Africa}^{26}$. In addition, both groups differ in their population trends; in contrast to Palaearctic migrants, Afro-Palaearctic migrants are experiencing major population declines across Europe for reasons that remain poorly understood ${ }^{35,36}$. More bird species per community dispersed seeds during the southward than during the northward migration (mean $=9.5$ and 5.9, respectively), a difference that was consistent across biomes (Extended Data Fig. 4). However, most of these species were Palaearctic migrants (Fig. 3a), particularly during the northward migration (mean $=87 \%$; direction, $P=0.005$ ) and in temperate communities (mean $=89 \%$; biome, $P=0.003$ ) (Extended Data Table 4). Furthermore, we found that both types of migrant differed in their functional relevance as seed dispersers, measured in terms of their interaction frequency (the proportion of the total interaction weight per network with all birds in migration (Methods)). Palaearctic migrants accounted for almost all interaction frequency (Fig. 3b), particularly during the northward migration (mean $=98 \%$; direction, $P<0.001$ ) (Extended Data Table 4$)$. Palaearctic migrants were also significantly more relevant in temperate ( mean $=98 \%$ ) than in Mediterranean communities (mean $=87 \%$; biome, $P<0.001$ ), in which Afro-Palaearctic birds had a more important role-particularly when migrating southwards (interaction of direction $\times$ biome, $P=0.008$ ) (Extended Data Table 4$)$. These results reveal that almost all seed-dispersal services towards cooler latitudes in Mediterranean (98\%) and temperate (99\%) communities across Europe are provided by a handful (about 5) of Palaearctic migrant species per locality. This stronger role of Palaearctic migrants can be explained by their occurrence in Europe during the winter (when invertebrates are scant and fruits abound) and their earlier spring migration northwards ${ }^{37}$.

Finally, we assessed the identity and importance of different bird species contributing to seed dispersal during their northward migration. For this, we obtained bird species strength, which measures the sum of plant dependencies (relative interaction frequencies) on each bird species and therefore quantifies the relevance of a bird species for community-wide seed dispersal towards cooler latitudes (Methods). To do so, we used subnetworks of the original networks that included only interactions during northward migrations (blue links in Fig. 1b). Then, we obtained the cumulative species strength per biome as the sum of species strengths across Mediterranean and temperate subnetworks (Fig. 3c). Results showed that a few Palaearctic migrants are disproportionately important during their northward migration. Across Mediterranean communities, the blackcap (Sylvia atricapilla) was by far the most important species, followed by the European robin (Erithacus rubecula) and the song thrush (Turdus philomelos) (Fig. 3c); these three species accounted for $73 \%$ of cumulative strength (blackcap, $49 \%$; robin, $15 \%$; and song thrush, 9\%). Across temperate communities, the blackbird (Turdus merula) was prominently the most relevant species, followed by the mistle thrush (Turdus viscivorus) and the fieldfare (Turdus pilaris) (Fig. 3c); these thrushes accounted for $69 \%$ of cumulative strength (blackbird, 44\%; mistle thrush, 15\%; and fieldfare, 10\%). Thus, bird species did not have similar relevance in both biomes (Extended Data Fig. 5). Notably, the key bird species for plant dispersal towards cooler latitudes are-in general-common and abundant birds, highlighting their importance for the functioning and dynamics of ecological communities ${ }^{38}$. However, their functional role in providing long-distance seed dispersal towards cooler latitudes could be at risk because bird migrations are already being disrupted by climate change $^{39,40}$. Moreover, some of these species are severely hunted (both legally and illegally), particularly in the Mediterranean region. In fact, S. atricapilla and T. philomelos are in the top five of the most 
illegally hunted birds in the Mediterranean Basin (estimated over 1 million individuals of each species killed per year ${ }^{41}$ ).

Available evidence shows that seed-dispersal distances by resident animals are typically insufficient for plants to track current climate change; however, it suggests that migratory birds can supply the long-distance dispersal services required (Supplementary Discussion 1). Given that our approach is based on mainstream migratory movements, our results provide a general template of the potential for directional, long-distance seed dispersal. A further step to accurately estimate dispersal distances and directionality requires detailed movement data of migratory birds, which are necessary for the development of mechanistic seed-dispersal models ${ }^{24}$. Such data are expected to come during this decade, as we are witnessing a revolution in next-generation GPS tags that will enable the tracking of small frugivorous birds with unprecedented spatiotemporal resolution ${ }^{42}$.

The Earth is warming rapidly and is expected to continue to do so in the near future ${ }^{2,8}$. Our study reveals that only about a third of fleshy-fruited plant species across European biomes will benefit from directed long-distance dispersal by migratory birds towards northern latitudes to track favourable conditions. These few 'winners' are phylogenetically clustered in plant lineages characterized by either long or late fruiting periods, and are mostly dispersed by a few common bird species with a relevance that is biome-specific. Our findings are expected to be broadly generalizable to other regions in the Northern Hemisphere (North America and Asia), where the fruiting period of most fleshy-fruited plants occurs in autumn ${ }^{43,44}$, when most birds move southwards, and where bird migration is a much more obvious phenomenon than in the Southern Hemisphere ${ }^{26}$. The extent to which our findings are generalizable to other plant-bird systems, such as aquatic plants dispersed internally or externally by waterbirds ${ }^{21,45,46}$, deserves further research. Understanding large-scale dispersal is necessary to develop conservation practices aimed at halting and mitigating biodiversity loss driven by climate change ${ }^{1}$. Our study suggests that migratory birds are only helping a phylogenetically clustered minority of plant species to disperse towards cooler latitudes, while they are dispersing most species towards increasingly drier and hotter regions. This divergent dispersal is expected to strongly influence the formation of novel communities in the future. Finally, our results provide a baseline to assess whether climate-driven phenological shifts will exacerbate or improve this situation.

\section{Online content}

Any methods, additional references, Nature Research reporting summaries, source data, extended data, supplementary information, acknowledgements, peer review information; details of author contributions and competing interests; and statements of data and code availability are available at https://doi.org/10.1038/s41586-021-03665-2.

1. Pecl, G. T. et al. Biodiversity redistribution under climate change: impacts on ecosystems and human well-being. Science 355, eaai9214 (2017).

2. Diffenbaugh, N. S. \& Field, C. B. Changes in ecologically critical terrestrial climate conditions. Science 341, 486-492 (2013).

3. Viana, D. S., Santamaría, L. \& Figuerola, J. Migratory birds as global dispersal vectors. Trends Ecol. Evol. 31, 763-775 (2016).

4. Bauer, S. \& Hoye, B. J. Migratory animals couple biodiversity and ecosystem functioning worldwide. Science 344, 1242552 (2014).

5. Corlett, R. T. \& Westcott, D. A. Will plant movements keep up with climate change? Trends Ecol. Evol. 28, 482-488 (2013).

6. Lenoir, J. \& Svenning, J. C. Climate-related range shifts - a global multidimensional synthesis and new research directions. Ecography 38, 15-28 (2015).

7. Lenoir, J. et al. Species better track climate warming in the oceans than on land. Nat. Ecol. Evol. 4, 1044-1059 (2020)

8. Loarie, S. R. et al. The velocity of climate change. Nature 462, 1052-1055 (2009).

9. Chen, I.-C., Hill, J. K., Ohlemüller, R., Roy, D. B. \& Thomas, C. D. Rapid range shifts of species associated with high levels of climate warming. Science 333, 1024-1026 (2011).
10. González-Varo, J. P., López-Bao, J. V. \& Guitián, J. Seed dispersers help plants to escape global warming. Oikos 126, 1600-1606 (2017)

11. Urban, M. C. et al. Improving the forecast for biodiversity under climate change. Science 353, aad8466 (2016)

12. Thuiller, W. et al. Predicting global change impacts on plant species' distributions: future challenges. Perspect. Plant Ecol. Evol. Syst. 9, 137-152 (2008).

13. Nadeau, C. P. \& Urban, M. C. Eco-evolution on the edge during climate change. Ecography 42, 1280-1297 (2019).

14. Bacles, C. F. E., Lowe, A. J. \& Ennos, R. A. Effective seed dispersal across a fragmented landscape. Science 311, 628 (2006).

15. Jordano, P., García, C., Godoy, J. A. \& García-Castaño, J. L. Differential contribution of frugivores to complex seed dispersal patterns. Proc. Natl Acad. Sci. USA 104, 3278-3282 (2007).

16. Breitbach, N., Böhning-Gaese, K., Laube, I. \& Schleuning, M. Short seed-dispersal distances and low seedling recruitment in farmland populations of bird-dispersed cherry trees. J. Ecol. 100, 1349-1358 (2012).

17. Cain, M. L., Damman, H. \& Muir, A. Seed dispersal and the Holocene migration of woodland herbs. Ecol. Monogr. 68, 325-347 (1998).

18. Nathan, R. et al. Spread of North American wind-dispersed trees in future environments. Ecol. Lett. 14, 211-219 (2011).

19. Nathan, R. et al. Mechanisms of long-distance seed dispersal. Trends Ecol. Evol. 23 , 638-647 (2008)

20. Viana, D. S., Gangoso, L., Bouten, W. \& Figuerola, J. Overseas seed dispersal by migratory birds. Proc. R. Soc. Lond. B 283, 20152406 (2016)

21. Viana, D. S., Santamaría, L., Michot, T. C. \& Figuerola, J. Migratory strategies of waterbirds shape the continental-scale dispersal of aquatic organisms. Ecography 36, 430-438 (2013).

22. Carlquist, S. The biota of long-distance dispersal. V. Plant dispersal to Pacific islands. Bull. Torrey Bot. Club 94, 129-162 (1967).

23. Esteves, C. F., Costa, J. M., Vargas, P., Freitas, H. \& Heleno, R. H. On the limited potential of Azorean fleshy fruits for oceanic dispersal. PLoS ONE 10, e0138882 (2015).

24. Viana, D. S., Santamaría, L., Michot, T. C. \& Figuerola, J. Allometric scaling of long-distance seed dispersal by migratory birds. Am. Nat. 181, 649-662 (2013)

25. Martínez-López, V., García, C., Zapata, V., Robledano, F. \& De la Rúa, P. Intercontinental long-distance seed dispersal across the Mediterranean basin explains population genetic structure of a bird-dispersed shrub. Mol. Ecol. 29, 1408-1420 (2020).

26. Newton, I. The Migration Ecology of Birds (Elsevier, 2010).

27. Sorensen, A. E. Interactions between birds and fruit in a temperate woodland. Oecologia 50, 242-249 (1981).

28. González-Varo, J. P., Arroyo, J. M. \& Jordano, P. The timing of frugivore-mediated seed dispersal effectiveness. Mol. Ecol. 28, 219-231 (2019).

29. Jordano, P. in Seeds: The Ecology of Regeneration of Plant Communities (ed. Gallagher, R. S.) $18-61(\mathrm{CABI}, 2014)$

30. Bascompte, J. \& Jordano, P. Mutualistic Networks (Princeton Univ. Press, 2013).

31. Gallinat, A. S. et al. Patterns and predictors of fleshy fruit phenology at five international botanical gardens. Am. J. Bot. 105, 1824-1834 (2018).

32. Cadotte, M. W. Experimental evidence that evolutionarily diverse assemblages result in higher productivity. Proc. Natl Acad. Sci. USA 110, 8996-9000 (2013).

33. Mitter, C., Farrell, B. \& Futuyma, D. J. Phylogenetic studies of insect-plant interactions: insights into the genesis of diversity. Trends Ecol. Evol. 6, 290-293 (1991).

34. Siemann, E., Tilman, D., Haarstad, J. \& Ritchie, M. Experimental tests of the dependence of arthropod diversity on plant diversity. Am. Nat. 152, 738-750 (1998).

35. Sanderson, F. J., Donald, P. F., Pain, D. J., Burfield, I. J. \& van Bommel, F. P. J. Long-term population declines in Afro-Palearctic migrant birds. Biol. Conserv. 131, 93-105 (2006).

36. Beresford, A. E. et al. Phenology and climate change in Africa and the decline of Afro-Palearctic migratory bird populations. Remote Sens. Ecol. Conserv. 5, 55-69 (2019).

37. Nilsson, C., Bäckman, J. \& Alerstam, T. Seasonal modulation of flight speed among nocturnal passerine migrants: differences between short- and long-distance migrants. Behav. Ecol. Sociobiol. 68, 1799-1807 (2014).

38. Gaston, K. J. Valuing common species. Science 327, 154-155 (2010)

39. Horton, K. G. et al. Phenology of nocturnal avian migration has shifted at the continental scale. Nat. Clim. Change 10, 63-68 (2020).

40. Miller-Rushing, A. J., Lloyd-Evans, T. L., Primack, R. B. \& Satzinger, P. Bird migration times, climate change, and changing population sizes. Glob. Change Biol. 14, 1959-1972 (2008).

41. Brochet, A.-L. et al. Preliminary assessment of the scope and scale of illegal killing and taking of birds in the Mediterranean. Bird Conserv. Int. 26, 1-28 (2016).

42. Kays, R., Crofoot, M. C., Jetz, W. \& Wikelski, M. Terrestrial animal tracking as an eye on life and planet. Science 348, aaa2478 (2015).

43. Stiles, E. W. Patterns of fruit presentation and seed dispersal in bird-disseminated woody plants in the eastern deciduous forest. Am. Nat. 116, 670-688 (1980).

44. Noma, N. \& Yumoto, T. Fruiting phenology of animal-dispersed plants in response to winter migration of frugivores in a warm temperate forest on Yakushima Island, Japan. Ecol. Res. 12, 119-129 (1997)

45. Lovas-Kiss, Á. et al. Shorebirds as important vectors for plant dispersal in Europe. Ecography 42, 956-967 (2019).

46. Coughlan, N. E., Kelly, T. C., Davenport, J. \& Jansen, M. A. K. Up, up and away: bird-mediated ectozoochorous dispersal between aquatic environments. Freshw. Biol. 62, 631-648 (2017)

Publisher's note Springer Nature remains neutral with regard to jurisdictional claims in published maps and institutional affiliations.

(c) The Author(s), under exclusive licence to Springer Nature Limited 2021 


\section{Methods}

No statistical methods were used to predetermine sample size. Randomization and blinding do not apply to our study, as we did not conduct experiments.

\section{Study seed-dispersal networks}

We refer to interacting communities of frugivorous birds that disperse the seeds of fruiting plants as networks, which are interaction matrices in which each row $i$ represents a plant species and each column $j$ represents a bird species. Elements in the matrices $\left(w_{i j}\right)$ denote whether pairwise plant-bird interactions were observed $\left(w_{i j}>0\right)$ or not $\left(w_{i j}=0\right)$ and-if so-their value account for interaction weight.

Our study includes 13 seed-dispersal networks evenly distributed between the Mediterranean $(n=6)$ and the temperate $(n=7)$ biomes of Europe ${ }^{47,48}$ (Fig. 1a and Extended Data Table 1). All these networks are quantitative (interactions are weighted) and were sampled in natural forests and woodlands, most of them in lowland habitats $(<600$ metres above sea level) in which agricultural fields surround the remnant vegetation. The single exception is the 'Nava Correhuelas' network, which is located on a well-preserved Mediterranean mountain at an elevation of 1,600 metres. Eight of the 13 networks include new data obtained by the authors, and five were compiled from previous studies ${ }^{27,49-51}$. Seven of the eight new networks were sampled within the EU project 'MobileLinks', through field sampling of bird-dispersed seeds and subsequent disperser identification by means of DNA-barcoding analysis ${ }^{52}$ (as described in 'Methods for the new network data'). The other six networks were obtained either through focal plant observations of birds feeding on fruits or through dietary analysis of birds captured in mist nets (Extended Data Table1). In networks obtained through focal observations, we focused exclusively on pairwise interactions in which the bird behaves as a legitimate seed disperser (swallowing the fruit and defecating or regurgitating viable seeds), discarding pulp-pecking and seed-predation interactions ${ }^{53}$.

Importantly, the study networks were sampled all year-round (for 1-6 years; mean $=2$ years), a prerequisite to cover the entire fruiting periods of all local fleshy-fruited species, as well as the prenuptial and postnuptial migration periods of all migratory birds; the single exception was the network from ref. ${ }^{27}$, which was sampled during nine months (August to early May), covering most of the year and both migrations (Extended Data Table 1). We thus avoided using other European networks ${ }^{54-56}$ that were sampled during short temporal periods (5-6 months). The study networks included a total of 949 interactions between frugivorous birds and fleshy-fruited plants (median $=52$ per network, range $=24-204$ ). Some interactions occurred in more than one network, resulting in 563 unique pairwise interactions between 46 bird species (median $=14$ per network, range $=8-21$ ) and 81 plant species (median $=15$ per network, range $=8-29$ ). The number of bird species, plant species or interactions did not differ significantly between Mediterranean and temperate networks ( $P \geq 0.20$ in one-way analyses of variance (ANOVAs) $\log _{10}[n] \sim$ biome). Bird and plant species included 16 and 28 families, respectively (Extended Data Table 2). The plants included trees and shrubs (79\% of species), herbs (11\%) and woody vines (10\%); thus, most plant species (89\%) were woody.

Because we were interested in the seed-dispersal function, we expressed the interaction weights $\left(w_{i j}\right)$ of all networks as the number of seeds of each plant species $i$ (or the seed-rain density as seeds per $\mathrm{m}^{2}$ ) dispersed by each bird species $j$. These weights were directly obtained in networks that sampled bird-dispersed seeds, either in seed traps for subsequent DNA-barcoding analysis or in droppings from birds captured in mist nets (as described in 'Methods for the new network data'. Yet, in networks based on feeding observations, interaction weights were originally expressed as number of bird visits to focal plants ${ }^{53}$. We then converted number of visits into number of seeds through the following two steps. First, we converted visits into fruits consumed using the parameters of a linear mixed model $\left(R_{\mathrm{GLMM}(m)}^{2}=0.924\right)$ fitted to data from two European networks ${ }^{56,57}$ for which the number of both visits and fruits consumed were recorded for each pairwise interaction (Supplementary Methods). In a second step, we converted fruits consumed into seeds dispersed by multiplying the former by the average number of seeds per fruit of each plant species, which was obtained from the literature ${ }^{50,58-60}$ and from data generated by the authors. In cases in which the product did not result in an integer, values were rounded to the nearest integer.

All networks were combined into a single data table for subsequent incorporation of data on seed-dispersal phenology and bird-migration periods (as described in 'Seed-dispersal phenology' and 'Migrant types and phenology of bird migrations'), with columns for network identity, network biome, network country and bioclimatic zone, plant and bird species, and interaction weight. Hereafter, we refer to 'seed-dispersal period' rather than to 'fruiting period' because a part of our phenological data was based on the presence of seeds dropped by birds in seed traps or during mist netting (as described in 'Methods for the new network data').

\section{Methods for the new network data}

Authorship of the eight unpublished networks is shown in the 'Author contributions' section.

MobileLinks networks. Community-wide seed dispersal by frugivorous birds was sampled within the EU project 'MobileLinks' (H2020-MSCA-IF-2014-656572) in seven European landscapes (plots of 1-4 $\mathrm{km}^{2}$ ) located in Spain, UK, Germany, Italy and Poland (Extended Data Table 1). Six of these plots were sampled for one year (2016-2017) and one plot for two complete years (2013-2015). In all plots, seed traps were placed beneath tree and shrub canopies (natural perches), and under electricity pylons (anthropogenic perches) used by birds, to quantify the magnitude of bird-mediated seed rain in the landscape ${ }^{61}$. Seed traps were $0.22-\mathrm{m}^{2}$ plastic trays covered with wire mesh to prevent postdispersal seed removal. Between 40 and 77 seed traps (mean $=46.3$ ) were monitored in each study plot. Sampling surveys, in which the number of bird-dispersed seeds per trap was recorded, were conducted fortnightly; seeds were visually identified (as described below in this section). The route used to survey the seed traps was also used as a 1-m wide single fixed belt transect (range 2,630-9,110 m length, mean $4,410 \mathrm{~m}$ ) to search for bird-dispersed seeds and quantify seed rain in canopy-free open interspaces, where bird-mediated seed rain is less likely ${ }^{61}$. Individual seeds or droppings with seeds were sampled for DNA barcoding analysis into 1.5 - or $2.0-\mathrm{ml}$ sterile tubes that were labelled and stored in a freezer at $-20^{\circ} \mathrm{C}$ until DNA extraction. Because DNA barcoding identification generally fails (PCR failure) in 5-10\% of samples ${ }^{28,52,61}$, some bird-dispersed seeds visually detected outside the transects were also sampled for DNA barcoding analysis aiming at increasing sample sizes, particularly for locally rare plant species. Conversely, only a subsample of the seeds was generally sampled when seed traps received many seeds of particular plant species; for example, 40-50\% of the hyper-abundant Pistacia lentiscus seeds in Garrapilos during its fruiting peak ${ }^{28}$.

We used DNA barcoding analysis (mitochondrial COI (cytochrome c oxidase subunit I)) to identify the bird species responsible for the seed-dispersal events, as DNA of animal origin can be extracted from the surface of defecated or regurgitated seeds ${ }^{28,52,61}$. Detailed laboratory protocols for DNA extraction, PCR, sequencing and species identification can be found in Supplementary Methods. Resulting sequences were identified at the species level based on best sequence matches in the 'BARCODE OF LIFE DATA' identification system $\left(\right.$ BOLD $\left.^{62}\right)$ (www. boldsystems.org), typically at a $98-100 \%$ similarity (Supplementary Fig. 1). We successfully identified the disperser species of 2,991 samples (that is, 2,991 sequences; $123-1,753$ per network) including 3,014 interaction events between a bird-plant species pair, and containing 
4,812 seeds (144-2,193 per network); overall 3,234 samples containing 5,181 seeds were analysed, with an identification success of $92.5 \%$ (PCR failure occurred in $7.5 \%$ of samples). All barcoding sequences obtained in the present study are publicly available in the data file 'MOBILELINKS_ DNA_barcoding_data.csv' deposited at the DRYAD repository (https:// doi.org/10.5061/dryad.15dv41nx3).

After DNA extraction for bird DNA barcoding, we visually identified seed species according to their morphology. To do so, we compared the seeds against a personal reference collection (owned by J.P.G.-V.) and pictures from a guide of seeds of European fleshy-fruited species that includes plants from the Mediterranean and temperate biomes ${ }^{58}$. The exception were 11 samples for which initial identification was not possible and for which we conducted DNA-barcoding analysis using chloroplast MaturaseK gene $\left(\right.$ matK$^{63}$ (detailed laboratory protocols are provided in Supplementary Methods). Seed species from these 11 samples were identified through the following three steps: (1) we obtained a short list of species from the best sequence matches in $\mathrm{BLAST}^{64}$; (2) we used such short list to identify candidate fleshy-fruited plant species that were present around the study sites; and (3) we used the final reduced list of candidate plant species to identify seed species visually according to seed morphology. Thus, this DNA-barcoding analysis served us to short list and guide visual identification (further details are provided in Supplementary Methods). All seed samples are stored by J.P.G.-V. at the Laboratory of Botany in the University of Cádiz, and plant sequences are publicly available in the data file 'MOBILELINKS DNA_barcoding_data.csv' deposited at the DRYAD repository (https:// doi.org/10.5061/dryad.15dv41nx3).

We used DNA barcoding identifications to calculate the relative contribution $\left(f_{i j k}\right)$ of each bird species $j$ to the seed-rain density of plant species $i$ beneath perch type $k$ as $f_{i j k}=n_{\mathrm{DNA}-i j k} / n_{\mathrm{DNA}-i k}$, in which $n_{\mathrm{DNA}}$ is the number of DNA-barcoded seeds. We then estimated the seed rain of each plant species dispersed by each bird species beneath different perch types as $s r_{i j k}=s r_{i k} \times f_{i j k}$, in which $s r_{i k}$ is average seed rain (seeds per $\mathrm{m}^{2}$ ) of plant species $i$ measured in seed traps located beneath perch type $k$ (similar to procedures in refs. ${ }^{28,65}$ ). Finally, we calculated the site-level (network-level) seed-rain density of each plant species dispersed by each bird species $\left(s r_{i j}\right)$ as the weighted mean of $s r_{i j k}$ values across perch types, using the number of seed traps per perch type as weighting factor. The result $\left(s r_{i j}\right)$ was the weight $\left(w_{i j}\right)$ of pairwise interactions in these networks, expressed as seeds per $\mathrm{m}^{2}$.

Vale Soeiro network. Community-wide seed dispersal by frugivorous birds was sampled in a plot of natural woodland of about $0.5 \mathrm{~km}^{2}$ located in central Portugal. A total of $168 \mathrm{~m}$ of mist nets of different lengths (nine mist nets of $15 \mathrm{~m}$, two of $12 \mathrm{~m}$ and one of $9 \mathrm{~m}$ ) were operated fortnightly during $5 \mathrm{~h}$ after dawn for 6 years (2012-2018). Nets were visited every $30 \mathrm{~min}$ and captured birds were individually placed in ringing bags for up to $30 \mathrm{~min}$ until they ejected droppings. Out of a total of 4,462 bird captures, 1,330 produced droppings with seeds ( $n=3,398$ seeds). Defecated or regurgitated seeds were later extracted and identified by comparison with a reference collection. A quantitative seed-dispersal network was built in which interaction weights $\left(w_{i j}\right)$ represented the total number of seeds of each plant species $i$ dispersed by each bird species $j$.

\section{Seed-dispersal phenology}

Seed-dispersal phenology is the period in which plants bear ripe fruits and disperse their seeds. We obtained bioclimate-level data on seed-dispersal phenology of the plant species in the study networks; the bioclimatic zone of the study networks is shown in Extended Data Table 1. We targeted on bioclimate-level phenology because the dispersal period of a given plant species may differ between bioclimatic zones $^{66}$. We used distinct data sources: published studies ${ }^{27,50,55,59,67-77}$, from which information was extracted from figures, tables and text; and our own data associated with the new eight networks that we obtained through fortnightly sampling surveys. Published studies included data on entire fleshy-fruited plant communities (for example, ref. ${ }^{67}$ ), in some cases associated to the published networks we compiled (for example, refs. ${ }^{50,59,72}$ ), as well as data on specific taxa (for example, refs. $\left.{ }^{68,70}\right)$. In some cases, we also used personal observations for the phenology of particular plant species at specific bioclimatic zones. From each data source, we obtained the 'start' and the 'end' of the seed-dispersal period ( $\left.D_{\text {start }}-D_{\text {end }}\right)$ of each plant species. We used a monthly scale (0-12) in which exact values represent the transition between months (for example, 0 = end of December-beginning of January; 1 = end of January-beginning of February; and so on) and half values represent the midpoint within months (for example, $1.5=$ mid-February). For instance, a fruiting period from mid-June to late September was expressed as $D_{\text {start }}=5.5$ and $D_{\text {end }}=9$. We added 12 to $D_{\text {end }}$ whenever it belonged to the next calendar year; hence, a dispersal period from mid-November to late March was expressed as $D_{\text {start }}=10.5$ and $D_{\text {end }}=15(3+12)$ (Extended Data Fig. 1). Most phenological data were obtained at a 0.5 -month accuracy (about 2 weeks), although in a few data sources the information was found at a 0.25 -month accuracy. We obtained data for 143 of the 150 unique 'plant species-bioclimate' combinations (95\%) from 288 original data entries as, in many cases, we obtained data from several sources or years for the same plant species at a particular bioclimate (Extended Data Fig. 6). When the same data source included information from different fruiting seasons (for example, refs. ${ }^{72,76}$ ), we averaged $D_{\text {start }}$ and $D_{\text {end }}$ values of each plant species across seasons. Then, we obtained unique $D_{\text {start }}$ and $D_{\text {end }}$ values for each plant species-bioclimate combination by averaging across data sources. With this procedure, we aimed at conservatively obtaining the most representative and generalizable seed-dispersal period of each plant species within each bioclimate. We also obtained the minimum $D_{\text {start }}$ and the maximum $D_{\text {end }}$ recorded (that is, the longest fruiting period per plant species-bioclimate combination) to perform a complementary analysis using a less conservative approach (Supplementary Discussion 2). For the seven remaining plant species-bioclimate combinations lacking specific information, we used data from the closest bioclimate. For example, we used phenological data of Rhamnus lycioides from thermo-Mediterranean bioclimate for one meso-Mediterranean network. Phenological data were finally incorporated into the network data according to plant species and network bioclimate.

\section{Migrant types and phenology of bird migrations}

We used published information ${ }^{59,78-85}$ and our own data (periodic bird censuses and mist netting captures) to classify the bird species in each study network as 'resident' (non-migrant), 'Palaearctic migrant' (birds that breed in Europe and winter in southern Europe and Africa north of the Sahara) and 'Afro-Palaearctic migrant' (birds that breed in Europe and winter in sub-Saharan Africa) ${ }^{26}$. Palaearctic migrants are often partial migrants (that is, only a fraction of their populations migrates while the other fraction behaves as resident $)^{26}$. For this reason, we characterized the proportion of migrants $\left(P_{\text {migrants }}\right)$ in the bird populations of the study networks by means of a semiquantitative variable: 0 , non-migrant population; 0.1 , only a minor fraction migrates; 0.25 , a larger fraction migrates but non-migrants prevail; 0.5 , roughly half of the population migrates; 0.75 , migrants prevail; 0.9 , only a minor fraction does not migrate; 1 : the whole population migrates (for this variable, we also used published information ${ }^{79,80,82-91}$ and our own data). Hence, Palaearctic migrants showed $P_{\text {migrants }}$ values ranging from 0.1 to 1. We also classified fully migrant populations $\left(P_{\text {migrants }}=1\right)$ as 'wintering', 'summer-breeding' or 'transient' depending, respectively, on whether birds occur locally during the winter, the breeding season or short periods while migrating (stopover site) ${ }^{26}$.

We obtained country-level phenological data for the prenuptial (northward) and postnuptial (southward) migrations of the bird species in the study networks (countries in Extended Data Table 1). In this 
case, we targeted on country-level phenology to capture geographical variation in the timing of migrations, as this information was obtained mainly from bird migration atlases of the study networks' countries: Spain and Portugal (Iberia) ${ }^{79,80}$, Italy ${ }^{82,83}$, UK $^{84}$, Germany ${ }^{86}$ and Poland ${ }^{87}$. We also obtained data from specific references from Poland ${ }^{88-91}$ and websites from recognized ornithological organizations in the case of Spain (www.seo.org/listado-aves-2) ${ }^{81}$ and the UK (www.birdtrack. net $)^{92}$. We gathered phenological data for the 119 unique 'bird speciescountry' combinations. From each data source, we obtained the 'start' and the 'end' of both the northward ( $N$, prenuptial) and southward $(S$, postnuptial) migration periods $\left(N_{\text {start }}-N_{\text {end }}\right.$ and $S_{\text {start }}-S_{\text {end, }}$, respectively) from figures, tables and text. All phenological data were obtained at a 0.5 -month accuracy (about 2 weeks). Again, we used a monthly scale in which exact values represent the transition between months and half values represent the midpoint within months (as described in 'Seed-dispersal phenology'). Only in 3 cases (2.5\% of the 119 bird species-country combinations) for which we did not obtain some of the four migration dates at the country level $\left(N_{\text {start }}-N_{\text {end }}\right.$ and $\left.S_{\text {start }}-S_{\text {end }}\right)$, we used migration phenology available for the Western Palaearctic region ${ }^{85}$ or at a continental coarse scale (www.eurobirdportal.org). Phenological data were finally incorporated into the network data according to bird species and network country.

\section{Directional migration in seed-dispersal interactions}

Phenological overlap during migrations. For each plant-bird interaction in each network, we calculated the phenological overlap between the seed-dispersal period of the plant and the northward and southward migration periods of the bird ( $O_{\text {north-ij }}$ and $O_{\text {south-ij }}$, respectively; $O$ units are months). We calculated these overlaps as the difference between the minimum 'end' and the maximum 'start' of both periods; $O_{\text {north-ij }}=\min \left(D_{\text {end }-i}, N_{\text {end }-j}\right)-\max \left(D_{\text {start }-i}, N_{\text {start }-j}\right)$, and $O_{\text {south-ij }}=\min \left(D_{\text {end }-i}\right.$, $\left.S_{\text {end }-j}\right)-\max \left(D_{\text {start- } i}, S_{\text {start }-j}\right)$. Before these calculations, we added 12 to the dates of the northward migration (spring) of bird species $j$ whenever the seed-dispersal period of plant species $i$ extended to the next calendar year (if $D_{\text {end }-i}>12$ ). This solved, for instance, the fact that a period of northward migration $N_{\text {start }-j}-N_{\text {end }-j}=2-4$ does not overlap mathematically with a seed dispersal period $D_{\text {start } i}-D_{\text {end }-i}=10-16$, despite there being a true phenological overlap $\left(N_{\text {start }-j}-N_{\text {end }-j}=2-4=14-16\right)$. Negative and 'NA' values obtained were converted into zeros (no overlap) as they represented, respectively, the lack of either phenological overlap or migration (resident birds). We provide a graphical representation for the overlap calculations of this section in Extended Data Fig. $1 \mathrm{~b}$ and Supplementary Fig. 3.

Total phenological overlap. Apart from the phenological overlap during migrations, we also calculated the total phenological overlap $\left(O_{\text {total }-i j}\right)$ as the whole period during which a bird species coincides locally with the seed-dispersal period of each plant species in the study networks. When bird populations were fully or partially resident $\left(P_{\text {migrants }}<1\right)$, the bird species occurs locally all year round and, thus, $O_{\text {total }-i j}$ was equal to the length of the seed-dispersal period $\left(O_{\text {total }-i j}=D_{\text {end }-i}-D_{\text {start }-i}\right)$. When bird populations were transient (only occur locally during migration), $O_{\text {total }-i j}$ was equal to the sum of phenological overlap during northward and southward migrations $\left(O_{\text {total }-i j}=O_{\text {north-ij }}+O_{\text {south- }-i j}\right)$. In the case of wintering migrants, their occurrence in the local communities spans from their arrival at the beginning of the southward migration $\left(S_{\text {start }}\right)$ to the end of their departure at the end of the northward migration $\left(N_{\text {end }}\right)$; thus, for wintering migrants: $O_{\text {total }-i j}=\min \left(D_{\text {end }-i}, N_{\text {end }-j}\right)-\max \left(D_{\text {start }-i}, S_{\text {start }-j}\right)$. In the case of summer migrants, their presence in local communities spans from their arrival at beginning of the northward migration $\left(N_{\text {start }}\right)$ to their complete departure at the end of the southward migration $\left(S_{\text {end }}\right)$; thus, for summer migrants: $O_{\text {total- } i j}=\min \left(D_{\text {end }-i}, S_{\text {end }-j}\right)-\max \left(D_{\text {start }-i}\right.$, $\left.N_{\text {start }-j}\right)$. Whenever $D_{\text {end }-i}$ extended to the next calendar year $\left(D_{\text {end }-i}>12\right)$, we added 12 to the migration dates to calculate the actual $O_{\text {total }-i j}$ (Supplementary Fig. 3).
Frequency of seed-dispersal interactions during migrations. We then used the phenological overlaps during migration $\left(O_{\text {north-ij }}\right.$ and $\left.O_{\text {south-ij } j}\right)$ and the total phenological overlap $\left(O_{\text {total-ij }}\right)$ to calculate, for each plant-bird interaction $i j$, the frequency of seed-dispersal interactions in which the bird is migrating northwards as $F_{\text {north }-i j}=P_{\text {migrants }-j} \times$ $O_{\text {north-ij/ }} / O_{\text {total }-i j}$, and southwards as $F_{\text {south- }-i j}=P_{\text {migrants }-j} \times O_{\text {south-ij } j} / O_{\text {total }-i j}$. The calculation was the fraction of the total phenological overlap accounted for by each migration period and weighted by the proportion of migrants in the bird population $\left(P_{\text {migrants }-j}\right)$. For instance, if $O_{\text {north-ij }}=3$ and $O_{\text {total }-i j}=6$, then $F_{\text {north }-i j}=0.5$ if the whole bird population migrates $\left(P_{\text {migrants }-j}=1 ; F_{\text {north-ij }}=1 \times 3 / 6\right)$, but $F_{\text {north-ij }}=0.05$ if only a minor fraction of the bird population migrates $\left(P_{\text {migrants }-j}=0.1 ; F_{\text {north-ij }}=0.10 \times 3 / 6\right)$. For fully resident populations, $O_{\text {north-ij }}, O_{\text {south-ij }}$ and $P_{\text {migrants }-j}$ equal 0 , and thus $F_{\text {north-ij }}$ and $F_{\text {south-ij }}$ too. We calculated the frequency of seed-dispersal interactions in which the bird is non-migrating as $F_{\text {non-ij }}=1-\left(F_{\text {north-ij }}+F_{\text {south-ij }}\right)$. Through this approach, we made the assumption that interaction frequency is uniformly distributed throughout $O_{\text {total }-i j}$. We consider it to be a conservative assumption because the magnitude of seed dispersal by frugivorous birds throughout the fruiting season can be roughly constant (our assumption), unimodal symmetric, unimodal skewed or even multimodal, depending on the plant species (for example, refs. ${ }^{27,50,71}$ ) and the local context (for example, ref. ${ }^{74}$ ).

Finally, for each plant species $i$ in each study network, we calculated the frequency of seed-dispersal interactions during which the birds are migrating south $\left(F_{\text {south- } i}\right)$, north $\left(F_{\text {north- } i}\right)$ or are not migrating $\left(F_{\text {non- } i}\right)$, as the weighted means of $F_{i j}$ across $j$ bird species. Weighting was done by the interaction weight $w_{i j}$ of each pairwise interaction. Hence, $F_{i}$ values represent the fraction of the total interaction weight of plant species dispersed by birds with distinct migratory states $\left(F_{\text {south } i}+F_{\text {north- } i}\right.$ $\left.+F_{\text {non }-i}=1\right)($ Extended Data Fig. 2$)$.

\section{Statistical analyses}

Four out of the 81 plant species (Crataegusmonogyna,Hedera hibernica, Rosa canina and Rubus fruticosus) actually represented operational taxonomic units in some networks owing to the local occurrence of congeneric species with seeds that did not allow for unambiguous species-level identification (Crataegus laevigata, Hedera maderensis, other Rosa and other Rubus species, respectively). In these cases, we used the name of the most common species to match the species name across networks, which allowed us to use plant species as random factor in mixed models and match a unique tip label in the plant phylogeny.

All generalized linear mixed models (GLMMs) described below were fitted using the R package gImmTMB (v.0.2.3 $)^{93}$ and the significance of fixed effects ( $P$ values of type II Wald $\chi^{2}$ tests) was computed using the Anova function of the R package car (v.2.1-6 ${ }^{94}$.

Seed-dispersal interactions. We fitted GLMMs to test whether the migration direction (southward or northward), the biome (Mediterranean or temperate) and the interaction between these two fixed factors were significantly associated with (1) the proportion of plant species (prevalence) interacting with birds during migration ( $n=434$ observations), (2) the frequency of seed-dispersal interactions with birds during migration (whenever these interactions occurred; non-zero $F_{i}$ ) out of the total interaction weight, and (3) the number of bird species dispersing each plant species during migration (whenever interactions during migration occurred; non-zero values); $n=260$ observations in (2) and (3). Importantly, the prevalence and frequency of interactions with migrants were not interrelated in both migrations (Supplementary Methods). All models included network identity and plant species nested within network as random factors (random intercepts) to account for the repeated measures per network (different plant species) and per plant species within networks (same plant interacting with birds migrating southwards and northwards). Prevalence among plant species was modelled as a Bernoulli-distributed variable with 
logit link function (1: $\left.F_{i}>0 ; 0: F_{i}=0\right)$. Frequency $\left(F_{i}>0\right)$ was modelled as a mixed-effects beta regression with logit link function in which the dispersion parameter $\phi$ of the beta distribution was allowed to vary in response to the interactive effects of direction and biome $(\Delta \mathrm{AIC}=-25$ relative to a model with fixed $\phi)^{95}$. For modelling purposes, we transformed $F_{i}$ values as follows: $F_{i}^{\prime}=\left(F_{i}(n-1)+0.5\right) / n$, in which $n$ is the total number of observations ${ }^{95}$. This transformation compresses the closed interval $(0 \leq y \leq 1)$ within the open interval $(0<y<1)$ because the values modelled by beta distribution are defined on the latter ${ }^{95}$ (range of $F_{i}>0: 0.0009-1$; range of $\left.F_{i}^{\prime}: 0.0020-0.9988\right)$; the estimated means and $95 \%$ confidence intervals reported in the Article (Fig. 2b) were previously back-transformed $\left(F_{i}=\left(F_{i}^{\prime} n-0.5\right) / n-1\right)$. The number of migrating bird species that dispersed each plant species was modelled as a Poisson-distributed variable with log link function.

Phylogenetic signal in plants. We tested for the presence of phylogenetic signal in the plant species means across networks regarding their interaction frequency ( $F_{i}$ values, including zeros) with birds migrating southwards and northwards, for all plant species $(n=81)$ and separately for species in Mediterranean and temperate networks ( $n=53$ and 45 , respectively). We calculated plant species means across networks because many plant species participated in several networks ( mean $=2.7$, range $=1-12$ ), either from the same or different biomes. For example, Cornus sanguinea participated in six temperate networks, Myrtus communis in four Mediterranean networks, and C. monogyna in 12 networks from both biomes. We extracted information about the phylogenetic relatedness of the plants present in the study networks from a dated phylogeny of seed plants (Spermatophyta) ${ }^{96}$ with a backbone based on a previous publication ${ }^{97}$. The tree was prepared by dropping tips other than the 81 plant species of interest using the R package ape (v.5.3) ${ }^{98}$; the resulting tree contained one polytomy, which was resolved randomly using the function multi2di. Phylogenetic signal was assessed through Pagel's $\lambda$ (ref. ${ }^{99}$ ), a statistic that varies between 0 (phylogenetic independence) and 1 (species' traits covary in direct proportion to their shared evolutionary history under a Brownian motion model of quantitative trait evolution $)^{100}$. Intermediate values of $\lambda$ indicate that traits have evolved according to a process in which the effect of phylogeny is weaker than in the Brownian model ${ }^{100}$. Pagel's $\lambda$ seems strongly robust to polytomies and suboptimal branch-length information ${ }^{101}$. Significant phylogenetic signal $(\lambda>0)$ is calculated through a likelihood ratio test comparing the likelihood of the model fitted to the data (observed $\lambda$ ) to that of a model in which $\lambda$ was fixed to $0^{100}$. These analyses were performed using the $\mathrm{R}$ package phytools (v.0.6-99 $)^{102}$. As a complementary analysis, we also tested for phylogenetic signal in seed-dispersal phenology as the frequency of interactions with migrant birds is ultimately related to fruiting phenology (Extended Data Fig. 3).

Migratory birds. We fitted GLMMs to test whether the migration direction, the biome and the interaction between these two fixed factors were significantly associated with the number of migratory bird species in the study networks dispersing plants during migration, and with the proportion of Palaearctic and Afro-Palaearctic species. The species richness was modelled as a Poisson-distributed variable with log link function and the proportion of Palaearctic species as a Bernoulli-distributed variable with logit link function (1: Palaearctic; 0 : Afro-Palaearctic; the proportion of both migrant types are fully interdependent). Network identity was included as a random factor (random intercepts) to account for the repeated measures within networks ( $n=26$ observations in each case, that is, 'network-direction' combinations). We also assessed whether the relevance of Palaearctic and Afro-Palaearctic migrants varied between migrations and biomes. To do so, we calculated the frequency of interactions with Palaearctic and Afro-Palaearctic birds on migration in each network out of the total interaction weight with all migrant birds during the southward and northward migrations (for example, $f_{\text {Palaearctic }}=W_{\text {Palaearctic }} / W_{\text {all migrants; }}$; in which $W_{\text {all migrants }}$ is the total interaction weight with all migrating birds per network, thus, $W_{\text {all migrants }}=W_{\text {Palaearctic }}+W_{\text {Afro-Palaearctic }}$ ). For this analysis, we used only data from Palaearctic migrants $\left(f_{\text {Palaearctic }}, n=26\right.$ observations, that is, network-direction combinations) because frequencies from both migrant types are fully interdependent $\left(f_{\text {Palaearctic }}+\right.$ $\left.f_{\text {Afro-Palaearctic }}=1\right)$. We fitted a GLMM to test whether the migration direction, the biome and their interaction were significantly associated with the interaction frequency with Palaearctic migrants. This model was as a mixed-effects beta regression with logit link function ${ }^{95}$, in which the dispersion parameter $\phi$ of the beta distribution was allowed to vary in response to the additive effects of direction and biome $(\triangle \mathrm{AIC}=-29$ relative to a model with fixed $\phi$ ). For modelling purposes, we transformed values for beta regression as explained in 'Seed-dispersal interactions' (range of $f_{\text {Palaearctic }}: 0.3818-1.0$; range of $f_{\text {Palaearctic }}^{\prime}: 0.3841-$ 0.9904); the estimated means reported in the article (Fig. 3b) were also back-transformed as explained in 'Seed-dispersal interactions'. Network identity was included as random factor (random intercepts) to account for the repeated measures within networks.

Finally, we used 'species strength', a species-level network metric ${ }^{103}$, to identify the most relevant bird species dispersing seeds during each migration. Species strength is the sum of plant dependencies (relative interaction frequencies) on each bird species, therefore, it quantifies the relevance of a bird species across all the fleshy-fruited plant community ${ }^{104}$. We calculated species strength of migratory birds $(n=24$ species) using the R package bipartite (v.2.13) ${ }^{103}$ in subnetworks of the original networks that only included seed-dispersal interactions either during southward or northward migration (subnetworks of red or blue links in Fig. 1b, respectively), in which strength quantifies the relevance of a bird species as a seed disperser during each migration. We then obtained the cumulative species strength (sum across sub-networks) per direction and biome combinations (Mediterraneansouthward, Mediterranean-northward, temperate-southward and temperate-northward). This way, very high cumulative values can only be found in migratory bird species with high strength values in several networks per biome. We used nonparametric Kendall's rank correlations to test whether, in each biome, the cumulative species strength across southward and northward subnetworks were correlated, which would indicate that bird species generally display a proportional role in both migrations (Extended Data Fig. 5). Besides, we used Kendall's rank correlations to test whether, for each migration, the cumulative species strength across Mediterranean and temperate subnetworks were correlated, which would indicate that bird species generally display a proportional role in both biomes (Extended Data Fig. 5).

\section{Reporting summary}

Further information on research design is available in the Nature Research Reporting Summary linked to this paper.

\section{Data availability}

All data used in the analyses are available through the Dryad Digital Repository (https://doi.org/10.5061/dryad.15dv41nx3). The dated phylogeny of seed plants (Spermatophyta) used to obtain our phylogenetic tree is available through GitHub (https://github.com/FePhyFoFum/big_seed_plant_trees/releases). Data on bird body weight used for size classification (Supplementary Fig. 2) were obtained from EltonTraits 1.0 available through Figshare (https://doi.org/10.6084/ m9.figshare.c.3306933).

\section{Code availability}

The R scripts used to generate all results and figures are available through the Dryad Digital Repository (https://doi.org/10.5061/ dryad.15dv41nx3). 
47. Olson, D. M. et al. Terrestrial ecoregions of the world: a new map of life on Earth: a new global map of terrestrial ecoregions provides an innovative tool for conserving biodiversity. Bioscience 51, 933-938 (2001).

48. Rivas-Martínez, S., Penas, A. \& Díaz, T. Bioclimatic Map of Europe, Thermoclimatic Belts (Cartographic Service, Univ. León, 2004).

49. Olesen, J. M. et al. Missing and forbidden links in mutualistic networks. Proc. R. Soc. Lond. B 278, 725-732 (2011)

50. Snow, B. \& Snow, D. Birds and Berries (T. and A. D. Poyser, 1988).

51. Stiebel, H. \& Bairlein, F. Frugivory in central European birds I: diet selection and foraging Vogelwarte 46, 1-23 (2008).

52. González-Varo, J. P., Arroyo, J. M. \& Jordano, P. Who dispersed the seeds? The use of DNA barcoding in frugivory and seed dispersal studies. Methods Ecol. Evol. 5, 806-814 (2014).

53. Simmons, B. I. et al. Moving from frugivory to seed dispersal: incorporating the functional outcomes of interactions in plant-frugivore networks. J. Anim. Ecol. 87, 995-1007 (2018).

54. Plein, M. et al. Constant properties of plant-frugivore networks despite fluctuations in fruit and bird communities in space and time. Ecology 94, 1296-1306 (2013).

55. Albrecht, J. et al. Variation in neighbourhood context shapes frugivore-mediated facilitation and competition among co-dispersed plant species. J. Ecol. 103, 526-536 (2015).

56. García, D. Birds in ecological networks: insights from bird-plant mutualistic interactions. Ardeola 63, 151-180 (2016).

57. Farwig, N., Schabo, D. G. \& Albrecht, J. Trait-associated loss of frugivores in fragmented forest does not affect seed removal rates. J. Ecol. 105, 20-28 (2017)

58. Torroba Balmori, P., Zaldivar García, P. \& Hernández Lázaro, Á. Semillas de Frutos Carnosos del Norte Ibérico: Guía de Identificación (Ediciones Univ. Valladolid, 2013).

59. Stiebel, H. Frugivorie bei Mitteleuropäischen Vögeln. PhD thesis, Univ. Oldenburg (2003).

60. Jordano, P. Data from: Angiosperm fleshy fruits and seed dispersers: a comparative analysis of adaptation and constraints in plant-animal interactions. Dryad https://doi. org/10.5061/dryad.9tb73 (2013).

61. González-Varo, J. P., Carvalho, C. S., Arroyo, J. M. \& Jordano, P. Unravelling seed dispersal through fragmented landscapes: frugivore species operate unevenly as mobile links. Mol. Ecol. 26, 4309-4321 (2017).

62. Ratnasingham, S. \& Hebert, P. D. N. bold: the Barcode of Life data system (http://www. barcodinglife.org). Mol. Ecol. Notes 7, 355-364 (2007).

63. CBOL Plant Working Group et al. A DNA barcode for land plants. Proc. Natl Acad. Sci. USA 106, 12794-12797 (2009).

64. Altschul, S. F. et al. Gapped BLAST and PSI-BLAST: a new generation of protein database search programs. Nucleic Acids Res. 25, 3389-3402 (1997).

65. González-Varo, J. P., Díaz-García, S., Arroyo, J. M. \& Jordano, P. Seed dispersal by dispersing juvenile animals: a source of functional connectivity in fragmented landscapes. Biol. Lett. 15, 20190264 (2019).

66. Fuentes, M. Latitudinal and elevational variation in fruiting phenology among western European bird-dispersed plants. Ecography 15, 177-183 (1992).

67. Herrera, C. M. A study of avian frugivores, bird-dispersed plants, and their interaction in Mediterranean scrublands. Ecol. Monogr. 54, 1-23 (1984).

68. Hampe, A. \& Bairlein, F. Modified dispersal-related traits in disjunct populations of bird-dispersed Frangula alnus (Rhamnaceae): a result of its Quaternary distribution shifts? Ecography 23, 603-613 (2000).

69. Thomas, P. A. \& Mukassabi, T. A. Biological flora of the British Isles: Ruscus aculeatus. J. Ecol. 102, 1083-1100 (2014).

70. Jordano, P. Biología de la reproducción de tres especies del género Lonicera (Caprifoliaceae) en la Sierra de Cazorla. An. Jardin Botanico Madr. 1979 48, 31-52 (1990).

71. Debussche, M. \& Isenmann, P. A Mediterranean bird disperser assemblage: composition and phenology in relation to fruit availability. Rev. Ecol. 47, 411-432 (1992).

72. Jordano, P. Diet, fruit choice and variation in body condition of frugivorous warblers in Mediterranean scrubland. Ardea 76, 193-209 (1988).

73. Barroso, Á., Amor, F., Cerdá, X. \& Boulay, R. Dispersal of non-myrmecochorous plants by a "keystone disperser" ant in a Mediterranean habitat reveals asymmetric interdependence. Insectes Soc. 60, 75-86 (2013).

74. González-Varo, J. P. Fragmentation, habitat composition and the dispersal/predation balance in interactions between the Mediterranean myrtle and avian frugivores. Ecography 33, 185-197 (2010).

75. Sánchez-Salcedo, E. M., Martínez-Nicolás, J. J. \& Hernández, F. Phenological growth stages of mulberry tree (Morus sp.) codification and description according to the $\mathrm{BBCH}$ scale. Ann. Appl. Biol. 171, 441-450 (2017).

76. García-Castaño, J. L. Consecuencias Demográficas de la Dispersión de Semillas por Aves y Mamiferos Frugívoros en la Vegetación Mediterránea de Montaña. PhD thesis, Univ. Sevilla (2001).

77. Gilbert, O. L. Symphoricarpos albus (L.) S. F. Blake (S. rivularis Suksd., S. racemosus Michaux). J. Ecol. 83, 159-166 (1995).

78. Billerman, S. M. et al. (eds) Birds of the World (Cornell Laboratory of Ornithology, 2020).

79. Tellería, J., Asensio, B. \& Díaz, M. Aves Ibéricas: II. Paseriformes (J. M. Reyero Editor, 1999).

80. Díaz, M., Asensio, B. \& Tellería, J. L. Aves Ibéricas: I. No paseriformes (J. M. Reyero Editor, 1996).

81. SEO/Birdlife. La Enciclopedia de las Aves de España (SEO/Birdlife-Fundación BBVA, 2019).

82. Spina, F. \& Volponi, S. Atlante della Migrazione degli Uccelli in Italia. 2. Passeriformi (Ministero dell'Ambiente e della Tutela del Territorio e del Mare, Istituto Superiore per la Protezione e la Ricerca Ambientale (ISPRA), Tipografia SCR-Roma, 2008).

83. Spina, F. \& Volponi, S. Atlante della Migrazione degli Uccelli in Italia. 1. Non-Passeriformi (Ministero dell'Ambiente e della Tutela del Territorio e del Mare, Istituto Superiore per la Protezione e la Ricerca Ambientale (ISPRA), Tipografia CSR-Roma, 2008).
84. Wernham, C. et al. The Migration Atlas: Movements of the Birds of Britain and Ireland (T. \& A. D. Poyser, 2002)

85. Cramp, S. The Complete Birds of the Western Paleartic (CD-ROM) (Oxford Univ. Press, 1998).

86. Bairlein, F. et al. Atlas des Vogelzugs - Ringfunde deutscher Brut- und Gastvögel (Aula, 2014).

87. Tomiałojć, L. \& Stawarczyk, T. Awifauna Polski: Rozmieszczenie, Liczebność i Zmiany (PTPP pro. Natura, 2003).

88. Busse, P., Gromadzki, M. \& Szulc, B. Obserwacje przelotu jesiennego ptaków w roku 1960 w Górkach Wschodnich koło Gdańska (Observations on bird migration at Górki Wschodnie near Gdańsk Autumn 1960). Acta Ornithologica 7, 305-336 (1963).

89. Bobrek, R. et al. Międzysezonowa powtarzalność dynamiki jesiennej migracji wróblowych Passeriformes nad Jeziorem Rakutowskim. Ornis Polonica 57, 39-57 (2016).

90. Keller, M. et al. Ptaki Środkowej Wisty (M-ŚTO, 2017).

91. Bocheński, M. et al. Awifauna przelotna i zimująca środkowego odcinka doliny Odry. Ptaki Śląska 16, 123-161 (2006).

92. BTO. BirdTrack. http://www.birdtrack.net (accessed October 2018).

93. Brooks, M. E. et al. glmmTMB balances speed and flexibility among packages for zero-inflated generalized linear mixed modeling. R J. 9, 378-400 (2017).

94. Fox, J. \& Weisberg, S. An R Companion to Applied Regression 2nd edn (SAGE, 2011).

95. Douma, J. C. \& Weedon, J. T. Analysing continuous proportions in ecology and evolution: a practical introduction to beta and Dirichlet regression. Methods Ecol. Evol. 10, 1412-1430 (2019).

96. Smith, S. A. \& Brown, J. W. Constructing a broadly inclusive seed plant phylogeny. Am. J. Bot. 105, 302-314 (2018).

97. Magallón, S., Gómez-Acevedo, S., Sánchez-Reyes, L. L. \& Hernández-Hernández, T. A metacalibrated time-tree documents the early rise of flowering plant phylogenetic diversity. New Phytol. 207, 437-453 (2015).

98. Paradis, E. \& Schliep, K. ape 5.0: an environment for modern phylogenetics and evolutionary analyses in R. Bioinformatics 35, 526-528 (2019).

99. Pagel, M. Inferring the historical patterns of biological evolution. Nature 401, 877-884 (1999).

100. Freckleton, R. P., Harvey, P. H. \& Pagel, M. Phylogenetic analysis and comparative data: a test and review of evidence. Am. Nat. 160, 712-726 (2002).

101. Molina-Venegas, R. \& Rodríguez, M. Á. Revisiting phylogenetic signal; strong or negligible impacts of polytomies and branch length information? BMC Evol. Biol. 17, 53 (2017).

102. Revell, L. J. phytools: an R package for phylogenetic comparative biology (and other things). Methods Ecol. Evol. 3, 217-223 (2012).

103. Dormann, C. F., Fründ, J., Blüthgen, N. \& Gruber, B. Indices, graphs and null models: analyzing bipartite ecological networks. Open Ecol. J. 2, 7-24 (2009).

104. Bascompte, J., Jordano, P. \& Olesen, J. M. Asymmetric coevolutionary networks facilitate biodiversity maintenance. Science 312, 431-433 (2006).

105. Bates, D., Maechler, M. \& Bolker, B. Ime4: linear mixed-effects models using 'Eigen' and S4. R package version 1.1-19 https://CRAN.R-project.org/package=Ime4 (2013).

Acknowledgements The 'Molecular Ecology Laboratory' (LEM-EBD-CSIC; ISO9001:2015 and ISO14001:2015 certifications) and the 'Research Unit of Biodiversity' (UO-CSIC-PA) provided logistical support for molecular analyses. We thank L. Viesca and E. Cires for laboratory assistance, and J. M. Varela for the bird illustrations. Barcoding data were obtained within an Individual Fellowship from the Marie Sklodowska-Curie Actions (H2020-MSCA-IF-2014-656572: MobileLinks) and supported by a GRUPIN grant from the Regional Government of Asturias (IDI/2018/000151). 'King Jaume I' awarded to A.T. supported data collation during two postdoctoral contracts. J.P.G.-V. is supported by a Spanish 'Ramon y Cajal' fellowship (RYC-2017-22095) and a grant from the Spanish MICINN (PID2019-104922GA-I00/AEI/10.13039/501100011033). B.R. is supported by a Spanish 'Juan de la Cierva Incorporación' fellowship (IJCI-2017-33475). R.H.H. is funded by the Portuguese Foundation for Science and Technology (UID/BIA/O4004/2020). B.I.S. is supported by a Royal Commission for the Exhibition of 1851 Research Fellowship. W.J.S. is funded by Arcadia.

Author contributions J.P.G.-V. conceived the study. J.P.G.-V., J.A., J.M.A., R.S.B., T.B., G.E.-Á., N.F., D.G., J.C.I., P.J., P.K., W.J.S. and E.V. obtained data of seven new seed-dispersal networks within the EU project 'MobileLinks'. J.M.A. and J.C.I. also conducted the molecular analyses for these networks. L.P.d.S. and R.H.H. provided data of one unpublished network. P.J. provided data of two published networks. B.R., J.P.G.-V. and A.T. gathered data on fruiting phenology and bird migrations; J.P.G.-V., B.R., J.A. and B.I.S. analysed the data; J.P.G.-V. wrote the first manuscript draft, and all authors worked on the final version.

Competing interests The authors declare no competing interests.

\section{Additional information}

Supplementary information The online version contains supplementary material available at https://doi.org/10.1038/s41586-021-03665-2.

Correspondence and requests for materials should be addressed to J.P.G.-V.

Peer review information Nature thanks Christiaan Both, Barnabas Daru, David Inouye, Duarte Viana and the other, anonymous, reviewer(s) for their contribution to the peer review of this work.

Reprints and permissions information is available at http://www.nature.com/reprints. 


\section{a}

range of a plant species $\square$ seed dispersal beyond the range

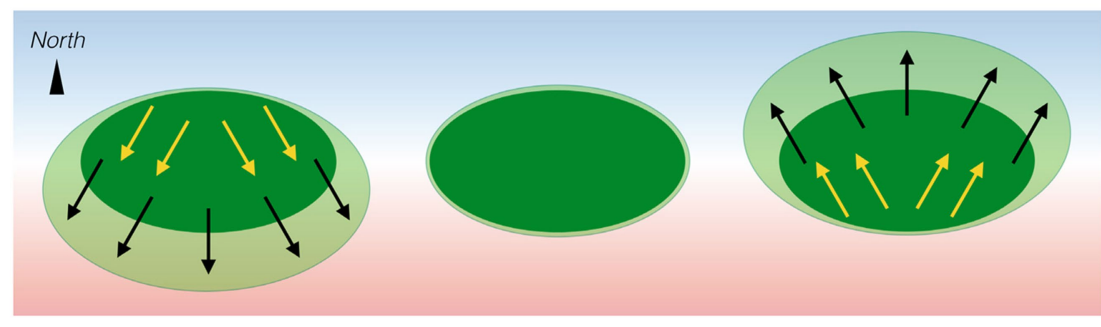

southward migration

no migration

northward migration

b
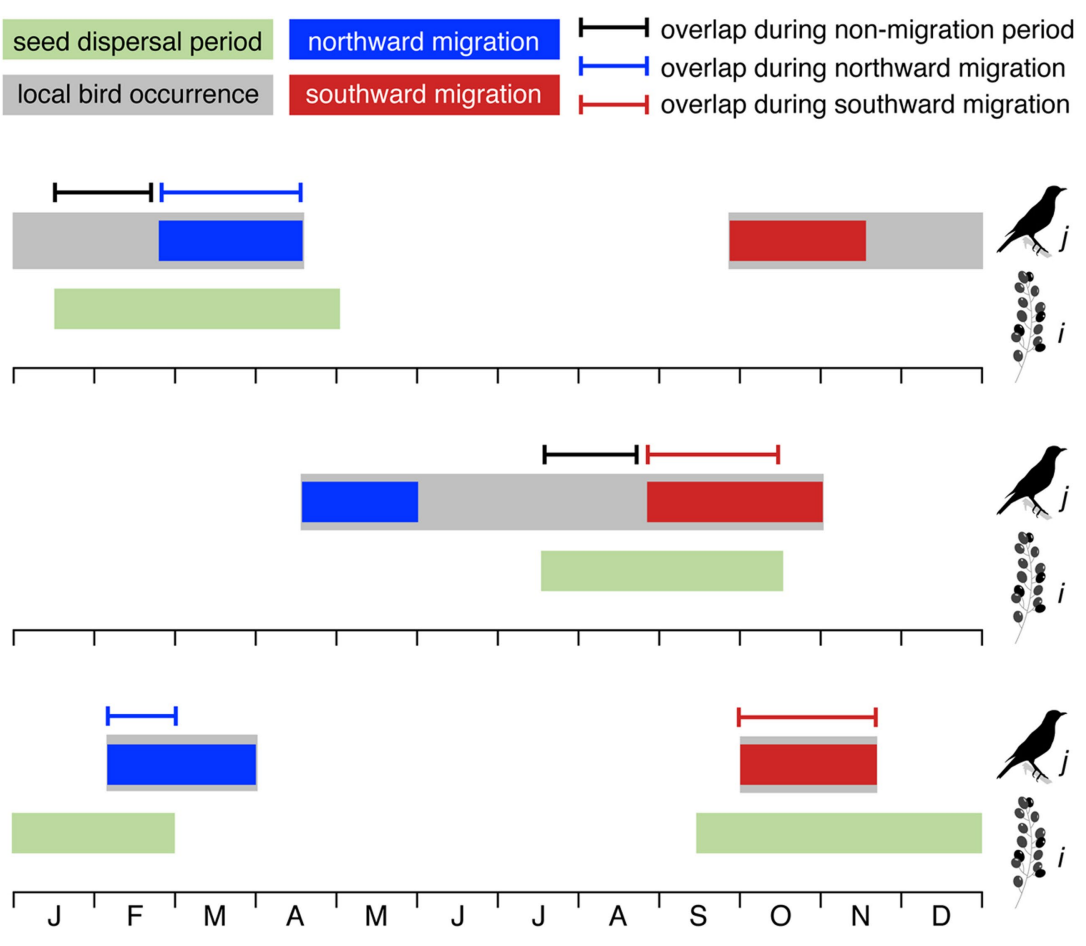

Extended Data Fig. 1 | Conceptual diagrams showing directional patterns of long-distance seed dispersal by migratory birds and phenological overlaps between seed-dispersal periods and bird migrations. a, Yellow and black arrows denote long-distance seed dispersal within and beyond the current range of a plant species, respectively. Seed dispersal mediated by birds migrating south (left), non-migrating birds (centre) and birds migrating north (right). The colour gradient from red to blue represents a climatic gradient from warmer to cooler latitudes (from south to north in the Northern Hemisphere), respectively. In the diagram on the right, seed dispersal within the range is necessary for warm-adapted populations to colonize cooler areas that are warming owing to climate change, whereas seed dispersal beyond the

range is necessary for range shifts. $\mathbf{b}$, Three hypothetical examples of phenological overlap between the seed-dispersal period of plant species $i$ and bird species $j$ while the bird migrates northwards (top), southwards (middle) or during both migrations (bottom). The examples include a wintering migrant with a winter-spring fruiting plant (top); a summer migrant with a summerautumn fruiting plant (middle); and a transient migrant with an autumn-winter fruiting plant (bottom). In some cases, there is also phenological overlap during non-migration periods. More details on phenological overlaps in relation to the migratory strategy of birds are provided in Supplementary Fig. 3. 


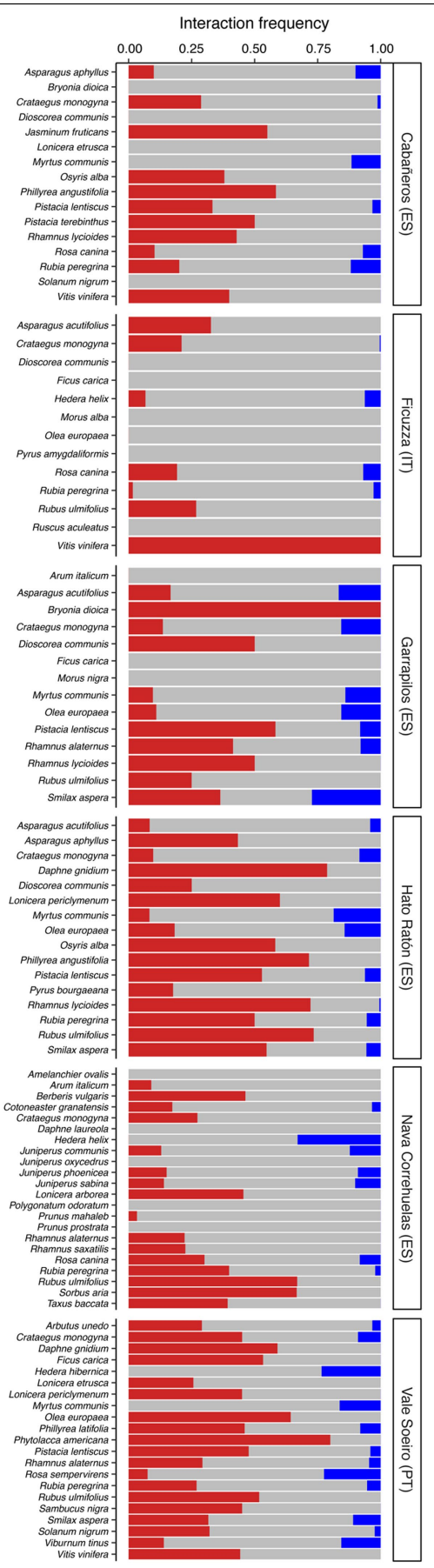

Mediterranean networks

E southward = no migration northward
Extended Data Fig. 2 | Estimated interaction frequencies of plant species within each study network with birds migrating northwards, southwards or not migrating. Blue, interactions during northward migration; red, interactions during southward migration; grey, non-migration interactions.

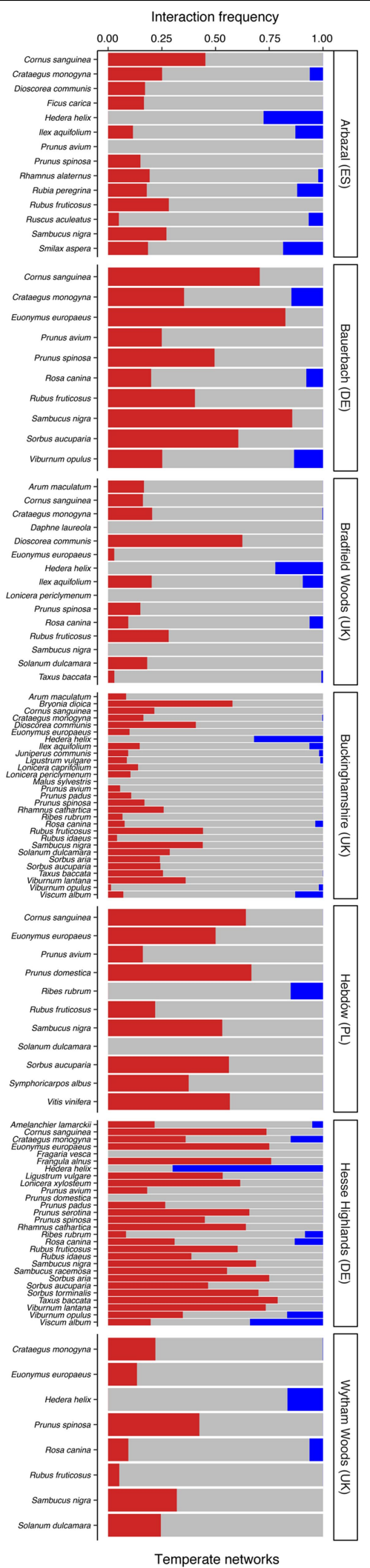

Each panel represents a seed-dispersal network. The left column of panels includes Mediterranean networks, whereas the right column includes temperate networks. DE, Germany; ES, Spain; IT, Italy; PL, Poland; PT, Portugal; UK, United Kingdom. 


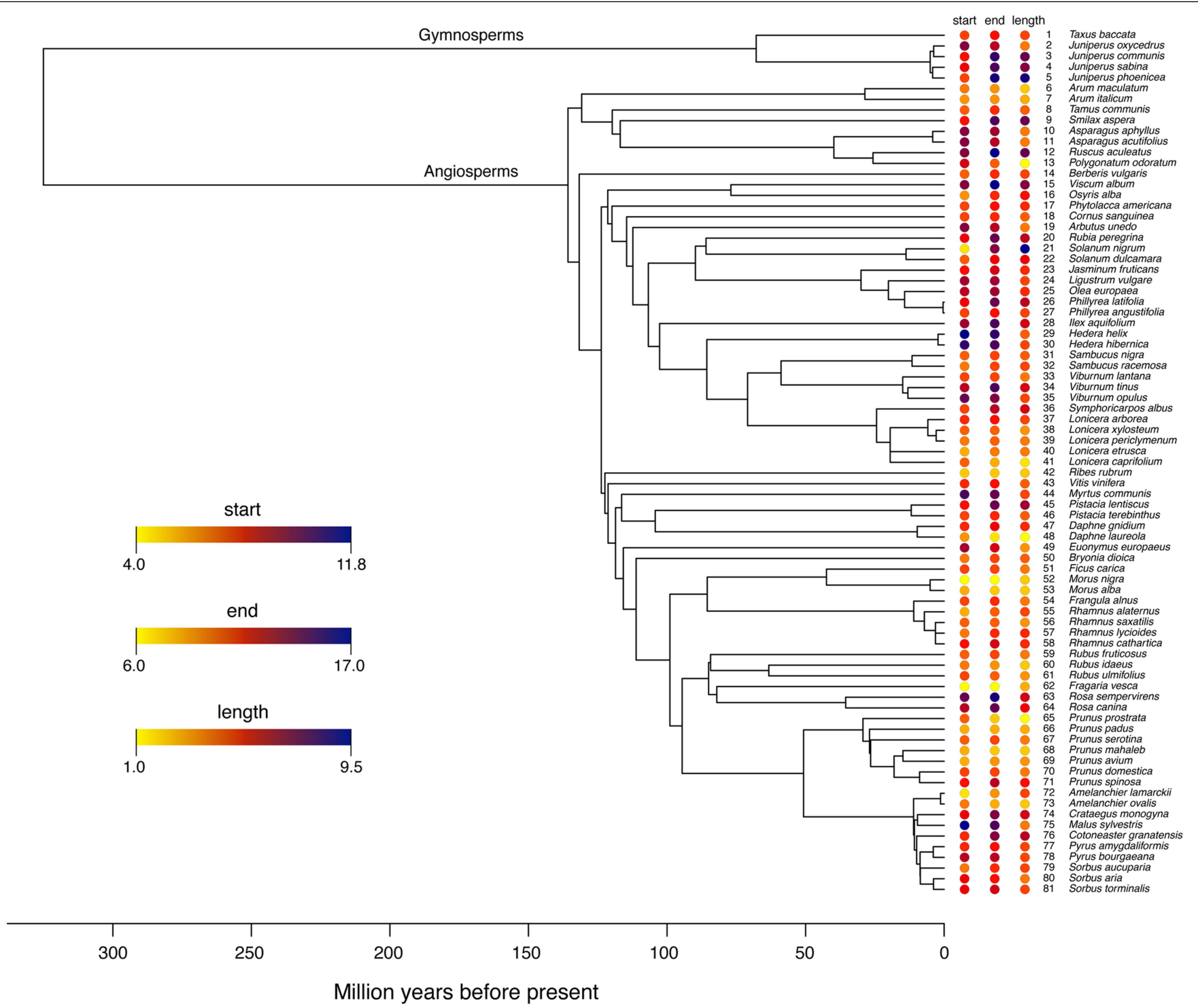

Extended Data Fig. 3 | Variables of the seed-dispersal phenology across the phylogenetic tree of plants. Phylogenetic signal was tested in plant-species means across networks in start and end dates $\left(D_{\text {start }}\right.$ and $\left.D_{\text {end }}\right)$, as well as in length $\left(D_{\text {length }}=D_{\text {end }}-D_{\text {start }}\right)$ of the seed-dispersal period ( $n=81$ plant species) by means of Pagels' $\lambda$, as described in 'Phylogenetic signal in plants' in 'Statistical analyses' (Methods). The three phenological variables showed significant phylogenetic signal $\left(D_{\text {start }}, \lambda=0.800, P=0.0103 ; D_{\text {end }}, \lambda=0.781, P=0.0015\right.$; and $D_{\text {length }}, \lambda=0.419, P=0.0343$ ). To test for phylogenetic signal, we previously calculated the species-level means for $D_{\text {start }}, D_{\text {end }}$ and $D_{\text {length }}$ across bioclimates (Extended Data Fig. 6). For this reason, we assessed the amount of variance in these phenological variables that is accounted for by bioclimate, as compared to that accounted for by species through linear-mixed models (LMMs) that included 'bioclimate' as fixed factor and 'plant species' as random factor to account for the repeated measures per species. Bioclimate accounted for only a minor fraction of variance (1-3\%) in $D_{\text {start }} D_{\text {end }}$ and $D_{\text {length }}$, as shown by the marginal $R^{2}$ values (variance explained by fixed effects; $R_{\text {LMM }(m)}^{2}=0.028,0.01$ and 0.023 , respectively). By contrast, the high conditional $R^{2}$ values (variance explained by both fixed and random effects; $R_{\text {LMM(c) }}^{2}=0.780,0.845$ and 0.643 , respectively) indicated that plant species accounted for most variance in the three phenological variables. LMMs were fitted with the R package package Ime4 (v.1.1-19) ${ }^{105}$. 


\section{Article}

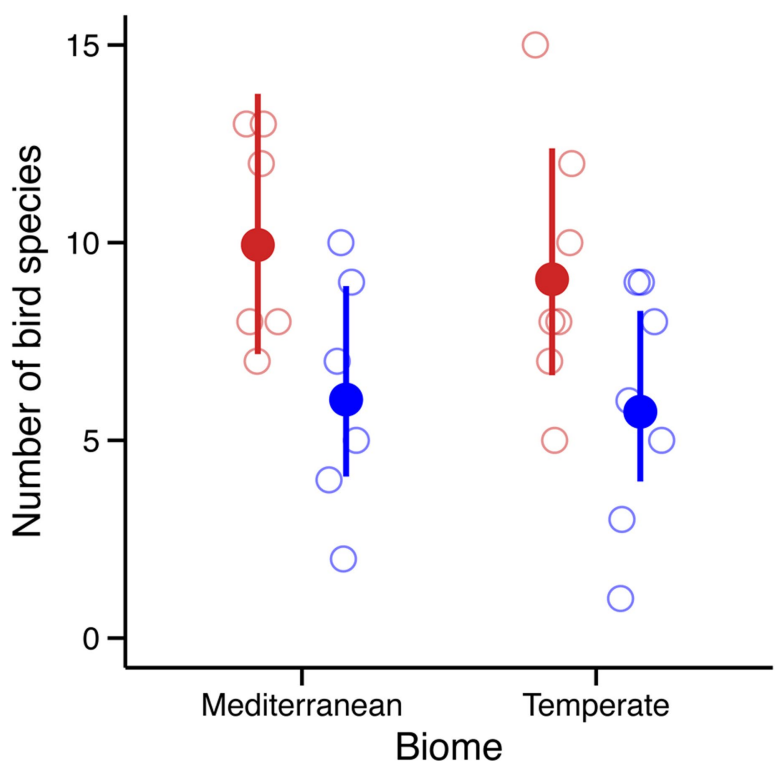

Extended Data Fig. 4 | Number of migratory bird species interacting with plants during migration per network in relation to migration direction and biome. Large dots and bars denote means $\pm 95 \%$ confidence intervals estimated by a GLMM, whereas circles denote values for each seed-dispersal network ( $n=26$ observations, 13 networks $\times 2$ directions). Only migration direction had significant effects on the number of migratory bird species interacting with plants during migration in the GLMM (Poisson family and $\log$-link function) testing the effects of migration direction (Wald $\chi^{2}=11.08$, $P=0.0009$ ), biome (Wald $\chi^{2}=0.17, P=0.6789$ ) and their interaction (Wald $X^{2}=0.02, P=0.8921$ ). Model estimates \pm s.e.: intercept $=2.297 \pm 0.156$; direction $($ northward $)=-0.500 \pm 0.208$; biome $($ temperate $)=-0.091 \pm 0.215$; direction (northward) $\times$ biome $($ temperate $)=0.039 \pm 0.288$; southward and Mediterranean were used as the reference categories (intercepts) for the factors direction and biome, respectively. A mean of 9.5 bird species per community dispersed plants during their southward migration, but only 5.9 species did so during the nor thward migration. 
Mediterranean

a

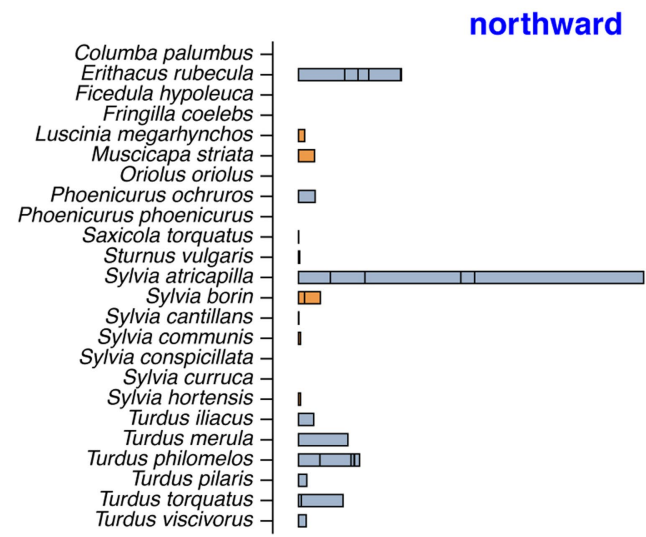

southward
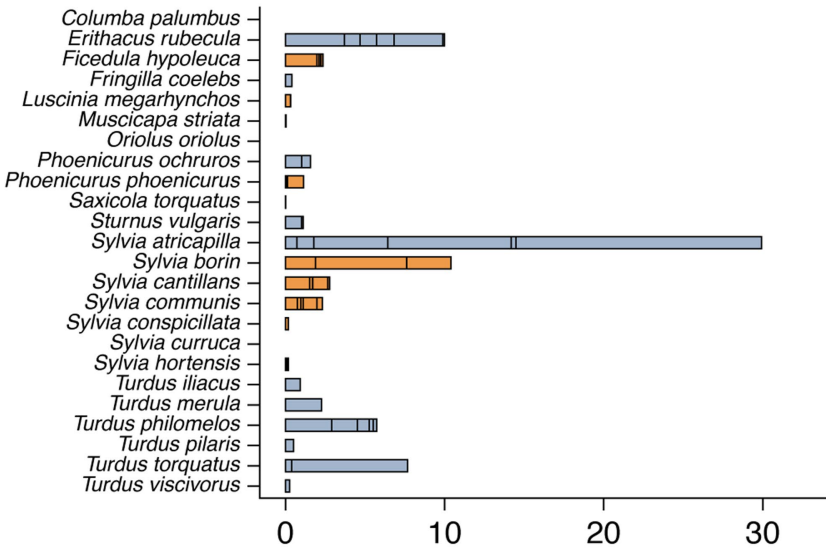

\section{Temperate}

northward

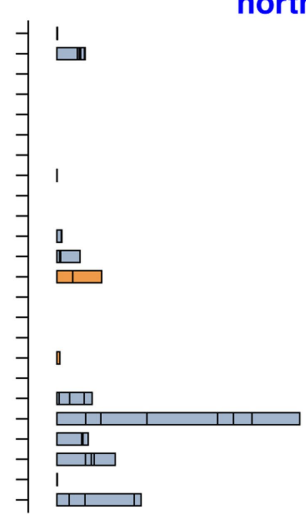

Palearctic migrants

Afro-Palearctic migrants

b

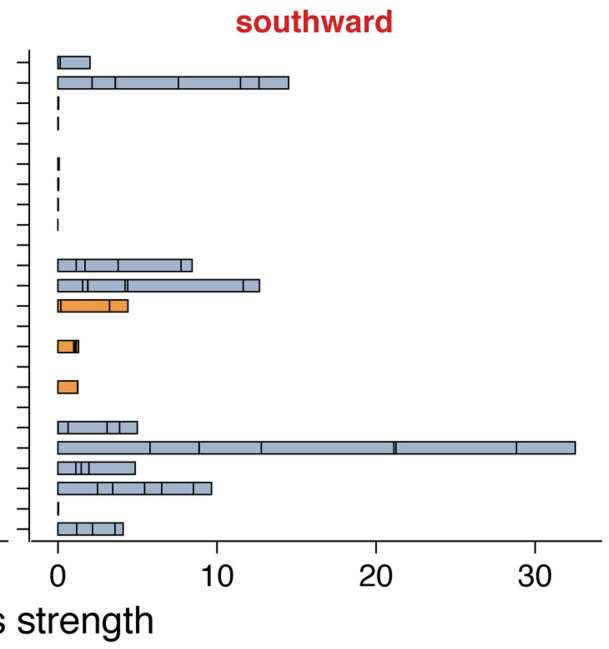

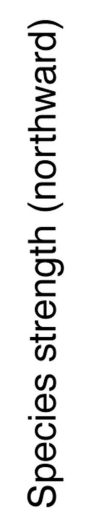
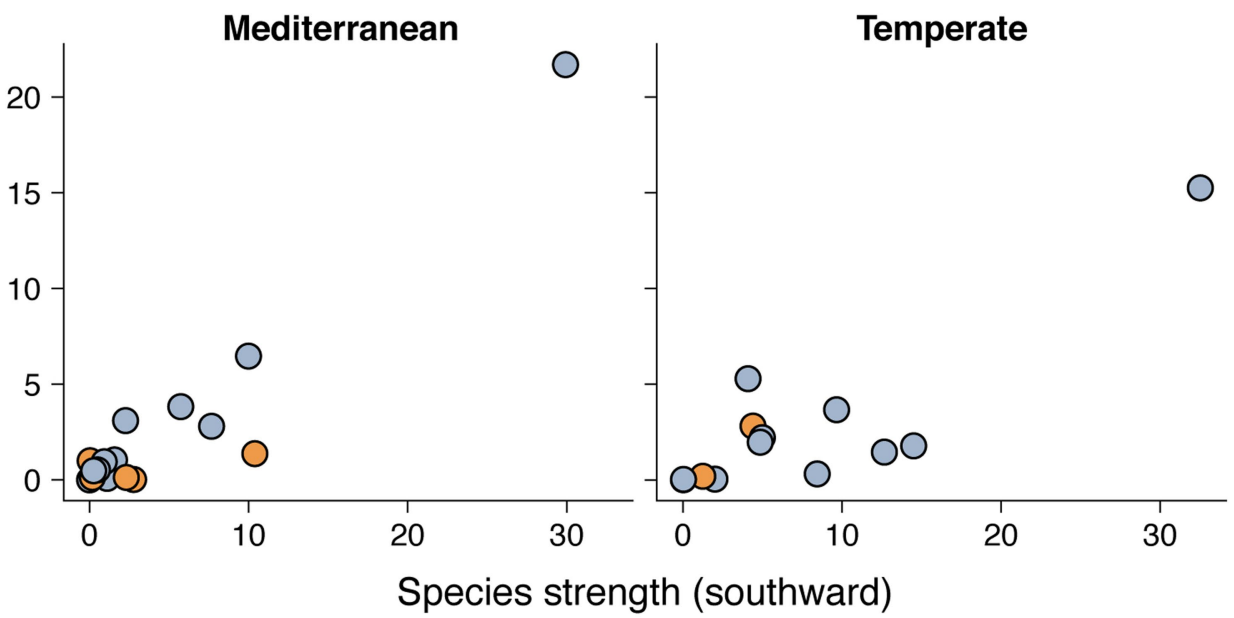

Extended Data Fig. 5 | Individual and cumulative bird species strengths accumulated across seed-dispersal subnetworks. a, Bird species strength accumulated across seed-dispersal subnetworks between plants and birds migrating southwards or northwards, and in Mediterranean and temperate biomes; species strength quantifies the relevance of a bird species across the entire fleshy-fruited plant community ${ }^{104}(n=24$ species). Some bird species have stacked values from several subnetworks, whereas other species participated only in a single subnetwork. b. The cumulative species strength across the southward and northward subnetworks were significantly correlated in the Mediterranean (Kendall's $\tau=0.396, P=0.0129$ ) and the temperate biome $(\tau=0.588, P=0.0006)$, indicating that bird species generally display a proportional role in both migrations. However, the cumulative species strength in the Mediterranean and temperate biome were not correlated, neither across the northward $(\tau=0.276, P=0.1089)$ nor across the southward subnetworks $(\tau=0.263, P=0.0764)$ (correlation between left and right panels in a). These results indicate discordance between biomes in the identity of bird species contributions to community-wide seed dispersal during each migration. Pearson's ryielded qualitatively similar results, with higher coefficient values in the significant correlations ( $r=0.946$ and 0.847$)$. 


\section{Article}

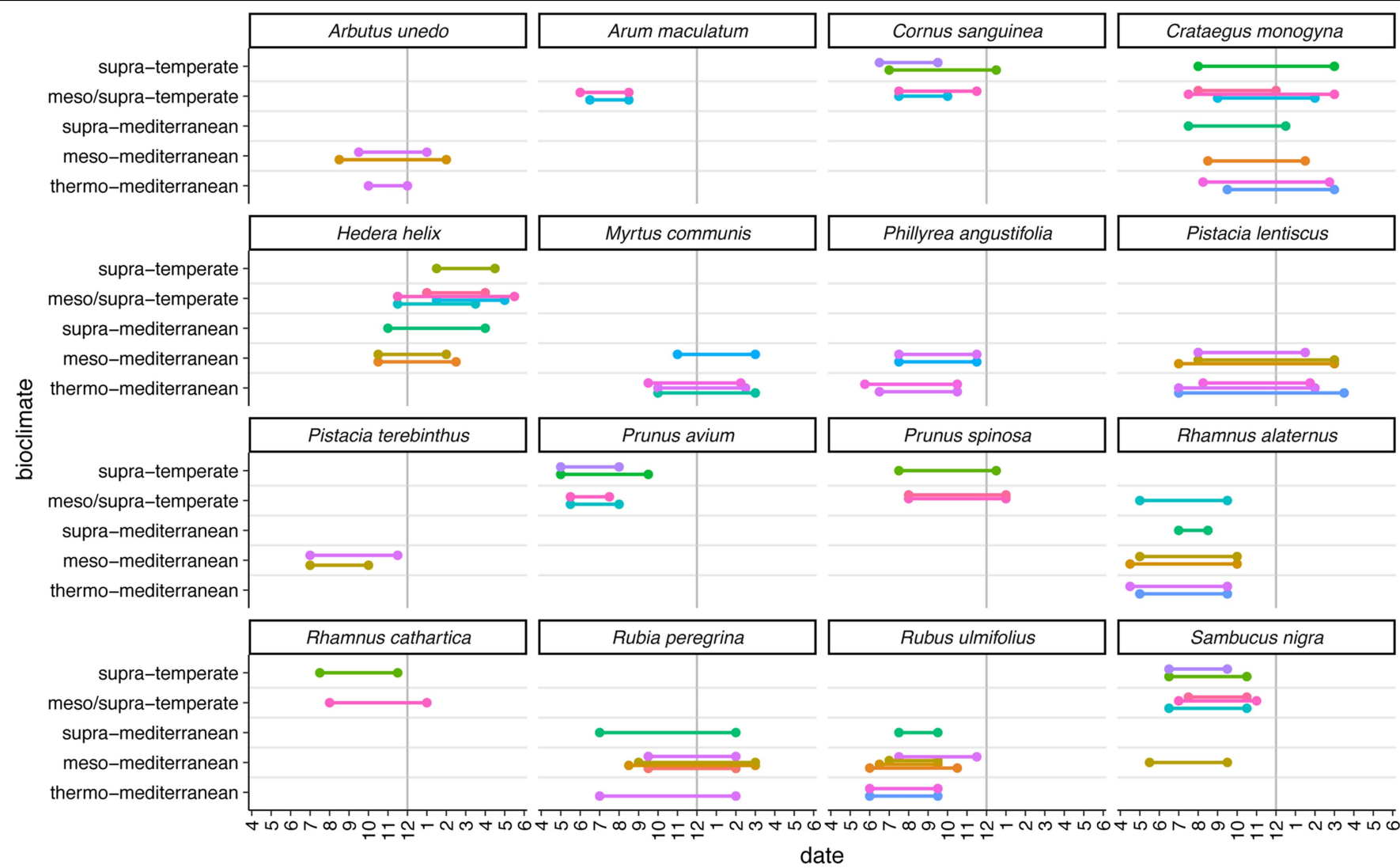

Extended Data Fig. 6 | Bioclimate-level plant phenology from several

sources. Subset of 16 out of the 81 plant species present in the study networks illustrating how, in many cases, we obtained data on seed-dispersal phenology from several sources for the same plant species-bioclimate combination. Colour codes denote different data sources. A vertical grey line divides the calendar year. 
Extended Data Table 1 | Characteristics of the European seed-dispersal networks that we studied

\begin{tabular}{|c|c|c|c|c|c|c|c|c|c|c|c|c|}
\hline $\mathbf{N}$ & Country & Network name & Source & Sampling type & Biome & Bioclimate & Latitude & Longitude & Years $(n)$ & $N_{\text {plant }}$ & $N_{\text {bird }}$ & $N_{\text {int }}$ \\
\hline 1 & Spain & Hato Ratón & A & Mist-netting & Mediterranean & thermo- & 37.1804 & -6.3240 & $1981-1983(2)$ & 16 & 17 & 120 \\
\hline 2 & Spain & Nava Correhuelas & A & Observations & Mediterranean & supra- & 37.9409 & -2.7927 & $1997-1999$ (2) & 22 & 21 & 111 \\
\hline 3 & Spain & Garrapilos & B & DNA-barcoding & Mediterranean & thermo- & 36.6589 & -5.9493 & 2013-2015 (2) & 14 & 21 & 56 \\
\hline 4 & Spain & Cabañeros & B & DNA-barcoding & Mediterranean & meso- & 39.3213 & -4.2896 & 2016-2017 (1) & 16 & 14 & 44 \\
\hline 5 & Spain & Arbazal & $B$ & DNA-barcoding & temperate & thermo/meso- & 43.4313 & -5.4971 & 2016-2017 (1) & 14 & 14 & 52 \\
\hline 6 & Portugal & Vale Soeiro & C & Mist-netting & Mediterranean & meso- & 40.3127 & -8.4035 & $2012-2018(6)$ & 21 & 13 & 76 \\
\hline 7 & Italy & Ficuzza & B & DNA-barcoding & Mediterranean & meso- & 37.8923 & 13.3749 & $2016-2017$ (1) & 13 & 12 & 30 \\
\hline 8 & UK & Buckinghamshire & $\mathrm{D}$ & Observations & temperate & meso/supra- & 51.8910 & -0.9120 & $1980-1985$ (5) & 29 & 19 & 204 \\
\hline 9 & UK & Wytham Woods & $E$ & Observations & temperate & meso/supra- & 51.7667 & -1.3333 & $1979-1980(1)$ & 8 & 8 & 24 \\
\hline 10 & UK & Bradfield Woods & B & DNA-barcoding & temperate & meso/supra- & 52.1808 & 0.8239 & 2016-2017 (1) & 15 & 11 & 36 \\
\hline 11 & Germany & Hesse Highlands & $\mathrm{F}$ & Observations & temperate & supra- & 51.3957 & 8.9427 & $1997-1999$ (2) & 28 & 18 & 128 \\
\hline 12 & Germany & Bauerbach & B & DNA-barcoding & temperate & supra- & 50.7950 & 8.8230 & 2016-2017 (1) & 10 & 9 & 30 \\
\hline 13 & Poland & Hebdów & B & DNA-barcoding & temperate & supra- & 50.1429 & 20.4274 & 2016-2017 (1) & 11 & 16 & 38 \\
\hline
\end{tabular}

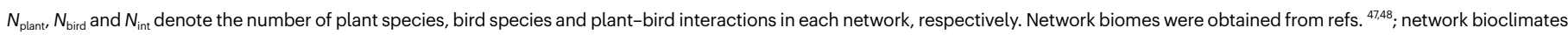

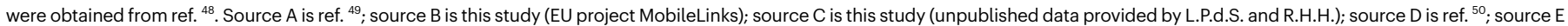
is ref. ${ }^{27}$; and source $\mathrm{F}$ is ref. ${ }^{51}$. 
Extended Data Table 2 | List of bird and plant species of the 13 study networks

\begin{tabular}{|c|c|c|c|c|c|}
\hline \multicolumn{2}{|c|}{ Bird species list } & \multicolumn{4}{|c|}{ Plant species list } \\
\hline Bird species & Bird family & Plant species & Plant family & Plant species & Plant family \\
\hline Alectoris rufa & Phasianidae & Amelanchier lamarckii & Rosaceae & Prunus avium & Rosaceae \\
\hline Columba palumbus & Columbidae & Amelanchier ovalis & Rosaceae & Prunus domestica & Rosaceae \\
\hline Corvus corax & Corvidae & Arbutus unedo & Ericaceae & Prunus mahaleb & Rosaceae \\
\hline Corvus corone & Corvidae & Arum italicum $\dagger$ & Araceae & Prunus padus & Rosaceae \\
\hline Corvus monedula & Corvidae & Arum maculatum $\dagger$ & Araceae & Prunus prostrata & Rosaceae \\
\hline Cyanistes caeruleus & Paridae & Asparagus acutifolius & Asparagaceae & Prunus serotina & Rosaceae \\
\hline Cyanopica cooki & Corvidae & Asparagus aphyllus & Asparagaceae & Prunus spinosa & Rosaceae \\
\hline Dendrocopos major & Picidae & Berberis vulgaris & Berberidaceae & Pyrus amygdaliformis & Rosaceae \\
\hline Emberiza calandra & Emberizidae & Bryonia dioicat & Cucurbitaceae & Pyrus bourgaeana* & Rosaceae \\
\hline Erithacus rubecula & Muscicapidae & Cornus sanguinea & Cornaceae & Rhamnus alaternus & Rhamnaceae \\
\hline Falco tinnunculus & Falconidae & Cotoneaster granatensis & Rosaceae & Rhamnus cathartica & Rhamnaceae \\
\hline Ficedula hypoleuca & Muscicapidae & Crataegus monogyna & Rosaceae & Rhamnus lycioides & Rhamnaceae \\
\hline Fringilla coelebs & Fringillidae & Daphne gnidium & Thymelaeaceae & Rhamnus saxatilis & Rhamnaceae \\
\hline Gallinula chloropus & Rallidae & Daphne laureola & Thymelaeaceae & Ribes rubrum & Grossulariaceae \\
\hline Garrulus glandarius & Corvidae & Euonymus europaeus & Celastraceae & Rosa canina & Rosaceae \\
\hline Lanius excubitor & Laniidae & Ficus carica & Moraceae & Rosa sempervirens & Rosaceae \\
\hline Luscinia megarhynchos & Muscicapidae & Fragaria vesca $\dagger$ & Rosaceae & Rubia peregrinat & Rubiaceae \\
\hline Muscicapa striata & Muscicapidae & Frangula alnus & Rhamnaceae & Rubus fruticosus & Rosaceae \\
\hline Oriolus oriolus & Oriolidae & Hedera helix & Araliaceae & Rubus idaeus & Rosaceae \\
\hline Parus major & Paridae & Hedera hibernicat & Araliaceae & Rubus ulmifolius & Rosaceae \\
\hline Phasianus colchicus & Phasianidae & Ilex aquifolium & Aquifoliaceae & Ruscus aculeatus & Asparagaceae \\
\hline Phoenicurus ochruros & Muscicapidae & Jasminum fruticans & Oleaceae & Sambucus nigra & Adoxaceae \\
\hline Phoenicurus phoenicurus & Muscicapidae & Juniperus communis & Cupressaceae & Sambucus racemosa & Adoxaceae \\
\hline Pica pica & Corvidae & Juniperus oxycedrus & Cupressaceae & Smilax aspera $\ddagger$ & Smilacaceae \\
\hline Picus sharpei & Picidae & Juniperus phoenicea & Cupressaceae & Solanum dulcamara† & Solanaceae \\
\hline Picus viridis & Picidae & Juniperus sabina & Cupressaceae & Solanum nigrum $\dagger$ & Solanaceae \\
\hline Saxicola torquatus & Muscicapidae & Ligustrum vulgare & Oleaceae & Sorbus aria & Rosaceae \\
\hline Sitta europaea & Sittidae & Lonicera arborea & Caprifoliaceae & Sorbus aucuparia & Rosaceae \\
\hline Streptopelia decaocto & Columbidae & Lonicera caprifolium $\ddagger$ & Caprifoliaceae & Sorbus torminalis & Rosaceae \\
\hline Sturnus unicolor & Sturnidae & Lonicera etruscał & Caprifoliaceae & Symphoricarpos albus & Caprifoliaceae \\
\hline Sturnus vulgaris & Sturnidae & Lonicera periclymenum & Caprifoliaceae & Dioscorea communis † & Dioscoreaceae \\
\hline Sylvia atricapilla & Sylviidae & Lonicera xylosteum & Caprifoliaceae & Taxus baccata & Taxaceae \\
\hline Sylvia borin & Sylviidae & Malus sylvestris & Rosaceae & Viburnum lantana & Adoxaceae \\
\hline Sylvia cantillans & Sylviidae & Morus alba & Moraceae & Viburnum opulus & Adoxaceae \\
\hline Sylvia communis & Sylviidae & Morus nigra & Moraceae & Viburnum tinus & Adoxaceae \\
\hline Sylvia conspicillata & Sylviidae & Myrtus communis & Myrtaceae & Viscum album & Santalaceae \\
\hline Sylvia curruca & Sylviidae & Olea europaea & Oleaceae & Vitis vinifera*: & Vitaceae \\
\hline Sylvia hortensis & Sylviidae & Osyris alba & Santalaceae & & \\
\hline Sylvia melanocephala & Sylviidae & Phillyrea angustifolia & Oleaceae & & \\
\hline Sylvia undata & Sylviidae & Phillyrea latifolia & Oleaceae & & \\
\hline Turdus iliacus & Turdidae & Phytolacca americana† & Phytolaccaceae & & \\
\hline Turdus merula & Turdidae & Pistacia lentiscus & Anacardiaceae & & \\
\hline Turdus philomelos & Turdidae & Pistacia terebinthus & Anacardiaceae & & \\
\hline Turdus pilaris & Turdidae & Polygonatum odoratum $\dagger$ & Asparagaceae & & \\
\hline Turdus torquatus & Turdidae & & & & \\
\hline Turdus viscivorus & Turdidae & & & & \\
\hline
\end{tabular}

We followed taxonomy from 'Birds of the World' (www.birdsoftheworld.org) $)^{78}$ for birds and a previously published ${ }^{96}$ phylogenetic tree (ALLMB) for plants. Plants are defined as herbs $\left({ }^{+}\right)$, woody vines (*) or trees and shrubs (all other species).

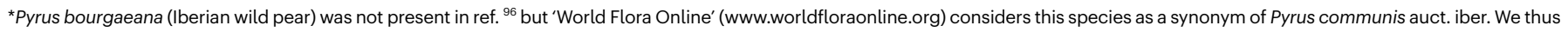
matched $P$. bourgaeana to $P$. communis in the phylogenetic tree to test for phylogenetic signal. 
Extended Data Table 3 | Significance of the fixed factors migration direction and biome, and their interaction, in GLMMs testing effects on seed-dispersal interactions of plants with migrating birds

\begin{tabular}{|c|c|c|c|}
\hline Fixed-effects & $\begin{array}{l}\text { (i) Proportion of plant } \\
\text { species } \\
\text { (Binomial, logit link) }\end{array}$ & $\begin{array}{l}\text { (ii) Frequency of seed-dispersal } \\
\text { interactions } \\
\text { (Beta, logit link) }\end{array}$ & $\begin{array}{c}\text { (iii) Number of bird species } \\
\text { per plant } \\
\text { (Poisson, log link) }\end{array}$ \\
\hline Hypothesis testing & $x^{2}$ & $x^{2}$ & $x^{2}$ \\
\hline Direction (D) & $2.0 \times 10^{-16}$ & $2.0 \times 10^{-16}$ & 0.0165 \\
\hline Biome (B) & 0.7612 & 0.6452 & 0.4142 \\
\hline$D \times B$ & 0.0080 & 0.0107 & 0.2623 \\
\hline Conditional model & Estimate \pm se & Estimate \pm se & Estimate \pm se \\
\hline Intercept & $1.414 \pm 0.310$ & $-0.418 \pm 0.207$ & $1.004 \pm 0.125$ \\
\hline D (northward) & $-1.734 \pm 0.368$ & $-1.842 \pm 0.164$ & $-0.307 \pm 0.124$ \\
\hline B (temperate) & $0.714 \pm 0.426$ & $-0.322 \pm 0.274$ & $0.085 \pm 0.168$ \\
\hline$D \times B$ & $-1.310 \pm 0.494$ & $0.642 \pm 0.251$ & $0.194 \pm 0.173$ \\
\hline Dispersion model & Estimate \pm se & Estimate \pm se & Estimate \pm se \\
\hline Intercept & - & $1.028 \pm 0.140$ & - \\
\hline D (northward) & - & $1.874 \pm 0.266$ & - \\
\hline B (temperate) & - & $0.754 \pm 0.198$ & - \\
\hline $\mathrm{D} \times \mathrm{B}$ & - & $-1.575 \pm 0.389$ & - \\
\hline Random effects & Variance & Variance & Variance \\
\hline Plant species: Network & 0.368 & $3.4 \times 10^{-9}$ & 0.157 \\
\hline Network & 0.077 & 0.174 & 0.052 \\
\hline
\end{tabular}

Proportion of plant species interacting with birds during migration ( $n=434$ observations) (i) (Fig. 2a), frequency of seed-dispersal interactions with birds during migration whenever these interactions occurred (non-zero frequencies; $n=260$ observations) out of the total interaction weight (ii) (Fig. 2b) and number of bird species dispersing each plant species during migration whenever these interactions occurred ( $n=260$ observations) (iii) (Fig. 2c). Family and link functions are shown in parentheses. All models included network identity and plant species nested

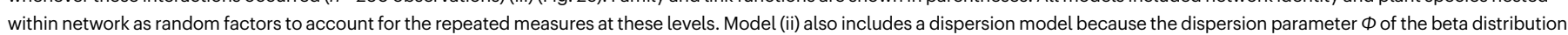
was allowed to vary in response to the interactive effects of direction and biome ${ }^{95}$. $P$ values (two-sided) $<0.05$ and significant model estimates $(P<0.05)$ are shown in bold.

In all models, southward and Mediterranean were used as the reference categories (intercepts) for the factors direction $(D)$ and biome $(B)$, respectively. 


\section{Article}

Extended Data Table 4 | Significance of the fixed factors migration direction and biome, and their interaction, in GLMMs testing effects on the proportion of migratory bird species that were Palaearctic migrants, and in the network-level frequency of seed-dispersal interactions with Palaearctic migrants

\begin{tabular}{|c|c|c|c|c|}
\hline \multirow{2}{*}{$\begin{array}{c}\text { Fixed-effects } \\
\text { Hypothesis testing }\end{array}$} & \multicolumn{2}{|c|}{$\begin{array}{l}\text { (I) Proportion of migratory bird species } \\
\text { that were Palearctic migrants } \\
\text { (Binomial, logit link) }\end{array}$} & \multicolumn{2}{|c|}{$\begin{array}{l}\text { (i) Interaction frequency during } \\
\text { migrations with Palearctic migrants } \\
\text { (Beta, logit link) }\end{array}$} \\
\hline & $x^{2}$ & $P$ & $x^{2}$ & $P$ \\
\hline Direction (D) & 7.98 & 0.0047 & 32.47 & $2.0 \times 10^{-16}$ \\
\hline Biome (B) & 9.14 & 0.0025 & 12.98 & 0.0003 \\
\hline $\mathrm{D} \times \mathrm{B}$ & 0.11 & 0.7458 & 7.12 & 0.0076 \\
\hline Conditional model & \multicolumn{2}{|c|}{ Estimate \pm se } & \multicolumn{2}{|c|}{ Estimate \pm se } \\
\hline Intercept & \multicolumn{2}{|c|}{$0.034 \pm 0.363$} & \multicolumn{2}{|c|}{$1.188 \pm 0.449$} \\
\hline D (northward) & \multicolumn{2}{|c|}{$1.004 \pm 0.466$} & \multicolumn{2}{|c|}{$2.508 \pm 0.503$} \\
\hline B (temperate) & \multicolumn{2}{|c|}{$1.429 \pm 0.534$} & \multicolumn{2}{|c|}{$2.219 \pm 0.531$} \\
\hline$D \times B$ & \multicolumn{2}{|c|}{$0.268 \pm 0.825$} & \multicolumn{2}{|c|}{$-1.516 \pm 0.568$} \\
\hline Dispersion model & \multicolumn{2}{|c|}{ Estimate \pm se } & \multicolumn{2}{|c|}{ Estimate \pm se } \\
\hline Intercept & \multicolumn{2}{|c|}{-} & \multicolumn{2}{|c|}{$1.318 \pm 0.560$} \\
\hline D (northward) & \multicolumn{2}{|c|}{-} & \multicolumn{2}{|c|}{$3.404 \pm 0.994$} \\
\hline B (temperate) & \multicolumn{2}{|c|}{-} & \multicolumn{2}{|c|}{$2.936 \pm 0.742$} \\
\hline Random effects & \multicolumn{2}{|c|}{ Variance } & \multicolumn{2}{|c|}{ Variance } \\
\hline Network & \multicolumn{2}{|c|}{0.336} & \multicolumn{2}{|c|}{0.088} \\
\hline
\end{tabular}

Family and link functions are shown in parentheses. Models included network identity as random factor to account for the repeated measures within networks $(n=26$ observations, 13 networks $\times 2$ directions). We used data only from Palaearctic migrants because the frequencies from both migrant types are fully interdependent (Fig. $3 a$, b). Model (ii) also includes a dispersion

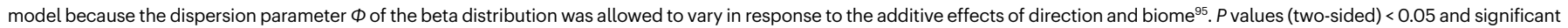
model estimates $(P<0.05)$ are shown in bold. Results for the species richness of all migrant species pooled are provided in Extended Data Fig. 4.

In all models, southward and Mediterranean were used as the reference categories (intercepts) for the factors direction $(D)$ and biome $(B)$, respectively. 


\section{Reporting Summary}

Nature Research wishes to improve the reproducibility of the work that we publish. This form provides structure for consistency and transparency in reporting. For further information on Nature Research policies, see our Editorial Policies and the Editorial Policy Checklist.

\section{Statistics}

For all statistical analyses, confirm that the following items are present in the figure legend, table legend, main text, or Methods section.

n/a $\mid$ Confirmed

$\bigotimes$ The exact sample size $(n)$ for each experimental group/condition, given as a discrete number and unit of measurement

$\square$ A statement on whether measurements were taken from distinct samples or whether the same sample was measured repeatedly

The statistical test(s) used AND whether they are one- or two-sided

Only common tests should be described solely by name; describe more complex techniques in the Methods section.

$\bigotimes$ A description of all covariates tested

$\bigotimes$ A description of any assumptions or corrections, such as tests of normality and adjustment for multiple comparisons

$\triangle$ A full description of the statistical parameters including central tendency (e.g. means) or other basic estimates (e.g. regression coefficient)

AND variation (e.g. standard deviation) or associated estimates of uncertainty (e.g. confidence intervals)

$\varnothing$ For null hypothesis testing, the test statistic (e.g. $F, t, r$ ) with confidence intervals, effect sizes, degrees of freedom and $P$ value noted Give $P$ values as exact values whenever suitable.

$\triangle \square$ For Bayesian analysis, information on the choice of priors and Markov chain Monte Carlo settings

$\square$ For hierarchical and complex designs, identification of the appropriate level for tests and full reporting of outcomes

$\square \bigotimes$ Estimates of effect sizes (e.g. Cohen's $d$, Pearson's $r$ ), indicating how they were calculated

Our web collection on statistics for biologists contains articles on many of the points above.

\section{Software and code}

Policy information about availability of computer code

Data collection Our study includes both data collection (field sampling and molecular analyses) and data compilation from previous studies. We used SEQUENCHER v. 4.9, BioEdit v. 7.0.9 and Chromas v. 2.5.1 for sequence alignment and editing. We used the online platforms BOLD (www.boldsystems.org) and BLAST (https://blast.ncbi.nlm.nih.gov/Blast.cgi) for species identification from amplified DNA sequences (i.e. DNA barcoding).

Data analysis We conducted all analyses in R version 3.5.2. We used the R packages glmmTMB (v. 0.2.3), car (v. 2.1-6), ape (v. 5.3), phytools (v. 0.6-99), Ime4 (v. 1.1-19) and bipartite (v. 2.13). We made the figures using the R packages 'ggplot2' (v. 3.3.0) and cowplot (v. 0.9.4). The R scripts used to generate all results and figures are available through the Dryad Digital Repository (https://doi.org/10.5061/dryad.15dv41n×3).

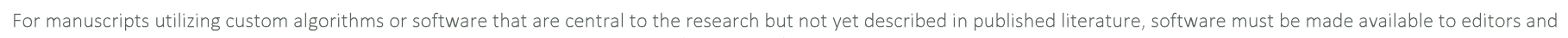

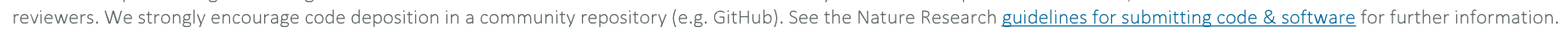

\section{Data}

Policy information about availability of data

All manuscripts must include a data availability statement. This statement should provide the following information, where applicable:

- Accession codes, unique identifiers, or web links for publicly available datasets

- A list of figures that have associated raw data

- A description of any restrictions on data availability

All data used in the analyses are available through the Dryad Digital Repository (https://doi.org/10.5061/dryad.15dv41nx3). The dated phylogeny of seed plants (Spermatophyta) used to obtain our phylogenetic tree is available through GitHub (https://github.com/FePhyFoFum/big_seed_plant_trees/releases). Data on bird 


\section{Field-specific reporting}

Please select the one below that is the best fit for your research. If you are not sure, read the appropriate sections before making your selection.

$\square$ Life sciences $\quad \square$ Behavioural \& social sciences $\quad$ Ecological, evolutionary \& environmental sciences

For a reference copy of the document with all sections, see nature.com/documents/nr-reporting-summary-flat.pdf

\section{Ecological, evolutionary \& environmental sciences study design}

All studies must disclose on these points even when the disclosure is negative.

Study description

Research sample

Sampling strategy

Data collection

Timing and spatial scale

Data exclusions

Reproducibility

Randomization
We combined phenological and migration information with data on 949 seed-dispersal interactions between 46 bird and 81 plant species from 13 woodland communities across Europe. The study design is factorial, as we tested the interactive effect between migration direction and community biome (direction $\mathrm{x}$ biome) on different response variables. The data structure is hierachical because we have species-level data for plants at birds nested within sites. The data structure also has repeated (paired) measures, with a data points per migration direction (southward and northward).

Research sample includes seed-dispersal networks, that is, interacting communities of 46 frugivorous bird species that disperse the seeds of 81 fruiting plant species from 13 woodland communities across Europe (see Extended Data Table 2). Seed dispersal networks are expressed as interaction matrices where each row i represents a plant species and each column j represents a bird species. Elements in the matrices (wij) denote whether pairwise plant-bird interactions were observed (wij $>0)$ or not $($ wij $=0$ ) and, if so, their value account for interaction weight. In this case, the quantity of seeds of each plant species dispersed by each bird species.

The total sample size for plants, the main subject of the study, includes 434 observations (i.e. "plant-species / site / migration" combinations).

Sex and age of the individuals is not relevant for the purposes of this study.

All the study networks $(n=13)$ were sampled all year-round, a prerequisite to cover the entire fruiting periods of all local fleshyfruited species, as well as the prenuptial and postnuptial migration periods of all migratory birds. Our study includes a combination of networks from previous studies $(n=5)$ and newly sampled networks $(n=8)$. The number of networks was evenly distributed between the Mediterranean $(n=6)$ and the temperate biomes $(n=7)$ of Europe, which allowed a sufficient sample size to test for biome effects.

Seven of the eight new networks were sampled through field sampling of bird-dispersed seeds and subsequent disperser identification by means of DNA-barcoding analysis. Individual seeds or droppings with seeds were sampled for DNA-barcoding analysis into $1.5-$ or $2.0-\mathrm{ml}$ sterile tubes that were labelled and stored in a freezer at $-20^{\circ} \mathrm{C}$ until DNA extraction. The molecular analyses for species identification was conducted by J.M.A. and J.C.I.

The other new network was sampled through dietary analysis of birds captured in mist nets. Captured birds were individually placed in ringing bags for up to 30 min until they ejected droppings.

The networks compiled from previous studies were obtained either through focal plant observations of birds feeding on fruits or through dietary analysis of birds captured in mist nets. Bird samples were collected in the field by J.P.G.-V., J.A., J.M.A., R.S.B., T.B. G.E.-A., N.F., D.G., J.C.I., P.J., P.K., W.J.S., E.V., L.P.d.S. and R.H. The networks from previous studies were compiled by B.I.S. Data on fruiting phenology and bird migrations was gathered by B.R., J.P.G.-V. and A.T.

New data in this study was collected between 2012 and 2018. Data available from previous studies were collected between 1981 and 1999. Sampling consisted on periodical surveys during 1-6 years, generally every 2 weeks, in which seed traps were revised, birds were mist-netted or focal plants were observed. Such frequency of sampling during all-year-round allows recording interactions between all bird adn plant species of each community, regardless the season. See details in Table S1. The data was collected in 13 sites across Europe and each site spans several square kilometers.

No data were excluded.

The analyses conducted in this study can be reproduced using the R code, which we will made publicly available once the article is accepted for publication. Moreover, we will make available in the DRYAD repository the complete dataset with the detailed information for each sample and its corresponding sequence obtained through DNA barcoding. The sequences include the sample code and all information associated: sampling date, site, seed species and number of seeds of the sample, bird species identified through DNA barcoding, percentage of similarity with best matched sequence and GenBank accession number of best matching sequence. In addition, we keep the DNA aliquots of all DNA extractions from each sample (voucher numbers correspond with 'sample_code') in our labs at University of Oviedo and EBD-CSIC (Spain). These aliquots are available under request. All seed samples are stored by J.P.G.-V at the laboratory of Botany in the University of Cádiz (Spain).

Randomization does not apply as we did not conduct experiments. However, we did assess potential biases regarding the sampling methods of study networks and the approach used to obtain seed-dispersal periods (see Supplementary Discussion 2; Supplementary Figures 5-7). 


\section{Field work, collection and transport}

Field conditions

We conducted fieldwork on several sites all year round during, for 1-6 years. The field conditions varied seasonally and between sites. The exact field conditions are not relevant because they do not impact the results. In the case of mit-netting, field work was only conducted when it was not raining.

Location

The latitude and longitude of the study sites is provided in Extended Data Table 1.

Access \& import/export

Permits to access to the study sites of the new data collected in this study (see Extended Data Table 1):

- Garrapilos (Spain): military site; permission given by "Servicio de Cría Caballar de las Fuerzas Armadas" to J.P.G.-V. (CC-42B00100-

S-13-5090; 16 October 2013).

- Cabañeros (Spain): national park; permission given by the director of the "Cabañeros National Park" to E.V. (June 2016).

- Arbazal (Spain): private site; permission given by local authority and owners to D.G. (February 2016).

- Vale Soeiro (Portugal): permission for mist-netting and bird ringing given by ICNF ("Instituto da Conservação da Natureza e das

Florestas") to L.P.d.S. (117/2012, 126/2013, 130/2014, 137/2015, 140/2016, 146/2017 and 123/2018).

- Ficuzza (Italy): private site; permission given by owners to R.S.B. (May 2016).

- Bradfield Woods (UK): natural reserve; permission given by "Suffolk Wildlife Trust" to J.P.G.-V. and W.J.S (30 March 2016).

- Bauerbach (Germany): public site; permission by local authority to N.F. (6 April 2016).

- Hebdów (Poland): public and private sites; permission by local authority and owners to P.K. (May 2016).

\section{Reporting for specific materials, systems and methods}

We require information from authors about some types of materials, experimental systems and methods used in many studies. Here, indicate whether each material, system or method listed is relevant to your study. If you are not sure if a list item applies to your research, read the appropriate section before selecting a response.

Materials \& experimental systems

\begin{tabular}{l|l}
\hline n/a & Involved in the study \\
$\square$ & $\square$ Antibodies \\
$\square$ & $\square$ Eukaryotic cell lines \\
$\square$ & $\square$ Palaeontology and archaeology \\
$\square$ & $\square$ Human research participants \\
$\searrow$ & $\square$ Clinical data \\
$\square$ & $\square$ Dual use research of concern
\end{tabular}

\section{Animals and other organisms}

Policy information about studies involving animals; ARRIVE guidelines recommended for reporting animal research

Laboratory animals

Wild animals

\begin{tabular}{l|l}
\multicolumn{2}{l}{ Methods } \\
\hline n/a & Involved in the study \\
$\bigotimes$ & $\square$ ChIP-seq \\
$\bigotimes$ & $\square$ Flow cytometry \\
$\square$ & $\square$ MRI-based neuroimaging
\end{tabular}

No laboratory animals were used in the study.

For sampling the seed-dispersal network from Portugal (Vale Soeiro), birds were caught in the field using mist-nets and immediately released in the same location after they ejected droppings in the cloth bag. No bird was injured, killed or kept captive.

Overall, 45 species were captured in a total of 4462 bird captures including 3123 individuals. In 1330 captures (846 individuals) of such captures, the bird produced droppings with seeds (13 bird species).

Full list of bird species captured ( $n=45$ species): Accipiter nisus, Acrocephalus scirpaceus, Aegithalos caudatus, Alcedo atthis, Anthus trivialis, Caprimulgus europaeus, Caprimulgus ruficollis, Carduelis chloris, Carduelis spinus, Certhia brachydactyla, Cyanistes caeruleus, Dendrocopos major, Erithacus rubecula, Ficedula hypoleuca, Fringilla coelebs, Fringilla montifringilla, Garrulus glandarius, Hippolais polyglotta, Lophophanes cristatus, Luscinia megarhynchos, Muscicapa striata, Parus major, Passer domesticus, Periparus ater, Phoenicurus ochruros, Phoenicurus phoenicurus, Phylloscopus collybita, Phylloscopus ibericus, Phylloscopus trochilus, Picus sharpei, Prunella modularis, Pyrrhula pyrrhula, Regulus ignicapillus, Serinus serinus, Streptopelia turtur, Sylvia atricapilla, Sylvia borin, Sylvia cantillans, Sylvia communis, Sylvia melanocephala, Sylvia undata, Troglodytes troglodytes, Turdus iliacus, Turdus merula and Turdus philomelos.

List of bird species that produced droppings with seeds ( $n=13$ species): Cyanistes caeruleus, Erithacus rubecula, Ficedula hypoleuca Parus major, Phoenicurus phoenicurus, Sylvia atricapilla, Sylvia borin, Sylvia cantillans, Sylvia communis, Sylvia melanocephala, Sylvia undata, Turdus merula and Turdus philomelos. 
Seed samples collected in the field were stored in the freezer at -20 으 until DNA-barcoding analyses.

Ethics oversight

No ethical approval was required as no bird was killed, injured or kept captive and we used normal procedures for mist-netting.

Note that full information on the approval of the study protocol must also be provided in the manuscript. 